\title{
Cambios didácticos en un profesor de física experto a partir del estudio de la ciencia como sistema cultural ${ }^{+*}$
}

\author{
Yeison Javier Cuesta Beltrán ${ }^{1}$ \\ Doctorado Interinstitucional en Educación \\ Universidad Distrital Francisco José de Caldas \\ Bogotá - Colômbia
}

\section{Resumen}

Este artículo presenta resultados de investigación sobre posibles cambios didácticos, en particular, de concepciones humanizantes sobre el conocimiento científico, a partir del estudio de la ciencia como sistema cultural por parte de un profesor universitario de fisica, quien enseña en la formación inicial de maestros. Este es un trabajo con orientación cualitativa, donde se realizó una Investigación Acción en la que se destacan tres etapas: diagnóstico, intervención y recolección final de información. El proceso permitió identificar algunos alcances, que desde nuestra perspectiva favorecen la formación del profesorado de fisica.

Palabras clave: Cambio Didáctico; Formación de Profesores de Física; Ciencia como Sistema Cultural

\begin{abstract}
This article presents research results on possible didactic changes, in particular, of more conscious conceptions of scientific knowledge, from the study of science as a cultural system by a university physics professor, who teaches at the initial training of teachers. This is a qualitative research, where an action research was carried out in which three stages stand out: diagnosis, intervention and final information
\end{abstract}

\footnotetext{
${ }^{+}$Didactic changes in an expert physics professor from on the study of science as a cultural system

* Recebido: fevereiro de 2020. Aceito: maio de 2020.

${ }^{1}$ E-mail: yjcuestab@correo.udistrital.edu.co
} 
gathering. The process allowed us to identify some scopes, which from our perspective favor the training of physics teachers.

Keywords: Didactic Change, Physics Teacher Training, Science as a Cultural System.

\section{Introducción}

Este artículo tiene como objetivo abordar los hallazgos de un proceso de investigación acción, en el que se pretendió favorecer cambios didácticos, en particular, de concepciones humanizantes sobre el conocimiento científico, en un profesor universitario de física, cuando se aborda el estudio de la ciencia como sistema cultural. Desde nuestra perspectiva, el sujeto estudiado es un caso destacable de investigación, ya que se trata de un profesor que desarrolla sus actividades en un programa universitario de formación inicial de profesores de física, en específico, enseñando en un curso de Física Cuántica (FC).

¿Por qué son importantes las concepciones sobre el conocimiento científico en el profesor?, una posible respuesta a este interrogante es que mucho de lo que piensa el maestro se ve reflejado en su práctica profesional, influyendo directamente en sus estudiantes quienes en cierta medida tomarán como ejemplo significativo las posturas de su profesor. Fernández et al. (2002) señalan que las concepciones de los maestros acerca de las ciencias, están involucradas en las deformaciones y reduccionismos que pueden obstaculizar la adecuada enseñanza del conocimiento científico. Estos autores afirman que:

Las concepciones docentes sobre la ciencia serían, pues, expresión de esa visión común, que los profesores de ciencias aceptaríamos implicitamente debido a la falta de reflexión crítica y a una educación científica que se limita, a menudo, a una simple transmisión de conocimientos ya elaborados. Ello no sólo deja en la sombra las características esenciales de la actividad cientifica, sino que contribuye a reforzar algunas deformaciones, como el supuesto carácter «exacto» (ergo dogmático) de la ciencia o la visión aproblemática, etc. De este modo, la imagen de la ciencia que poseen los docentes se diferenciaría poco de la que puede expresar cualquier ciudadano y resulta muy alejada de las concepciones actuales acerca de la naturaleza de la ciencia. De ahi la importancia de un trabajo de clarificación que permita a los docentes distanciarse críticamente de estas visiones deformadas (FERNÁNDEZ et al., 2002, p. 484).

Es necesario aclarar qué entendemos por concepción. Esta palabra etimológicamente se relaciona con concebir, un verbo que puede hacer referencia a entender, comprender, fecundar. En el marco del constructivismo una concepción estaría íntimamente ligada a la elaboración personal, a la comprensión sobre un tema determinado, en este caso particular, sobre la naturaleza del conocimiento científico. Cabe señalar que las concepciones pueden ser 
consideradas adecuadas o no, dependiendo de la aceptación social de las mismas. Así mismo, es oportuno abordar la noción de visión, que desde la etimología expresa la acción y efecto de ver, verbo que en sus raíces se relaciona con el origen de la palabra eidos, que puede considerarse apariencia, imagen, aspecto. Es de destacar que las visiones sobre un determinado tema presentan carácter personal para cada individuo, actitudes elaboradas a partir de las vivencias, y sus formas individuales o grupales de ver el mundo. En este contexto en específico, hace referencia a la imagen que elabora cada sujeto sobre el conocimiento científico.

Sobre el conocimiento científico y su naturaleza, existen aproximaciones habituales a las que hace referencia Chalmers (2000), quien señala que el empirismo y el positivismo forman escuelas que promueven una visión común en la que se considera que este conocimiento se deriva de los hechos. Fernández et al. (2002) expanden el panorama acerca de estas aproximaciones habituales considerando que comúnmente se fomentan las siguientes nociones: 1. el empiroinductivismo, en donde se considera que se llega al conocimiento científico a través de la experimentación neutra, ajena a las ideas aprioris; 2. el positivismo, que promueve una visión rígida de la actividad científica, considerando para su elaboración un único método con enfoque principalmente cuantitativo a partir del cual se proclama la rigurosidad; 3. el enfoque aproblemático y ahistórico, en el que se considera destacable el conocimiento ya elaborado, omitiendo las problemáticas que posibilitaron su origen, su construcción, su desarrollo, sus dificultades y sus limitaciones; 4. el enfoque exclusivamente analítico, en el que se destaca la necesaria división inicial de los estudios científicos, su carácter simplificador, olvidando los posteriores esfuerzos de unificación; 5. enfoque acumulativo del desarrollo en ciencias, en el que se considera el conocimiento científico como producto de un crecimiento lineal y acumulativo, sin tener en cuenta las crisis y rupturas epistemológicas. 6. el enfoque individualista y elitista, en el que el conocimiento se considera obra de genios aislados, sin reconocer el papel del trabajo colectivo, mostrando que las ciencias naturales son exclusivas para los especialistas.

En general, las aproximaciones habituales sobre el conocimiento científico consideran que este es jerárquico con respecto a otros saberes, destacando que sus elaboraciones sobre la naturaleza son fieles e irrefutables, ubicando esta construcción en un marco donde lo científico difícilmente tiene la posibilidad de ser negado. Así mismo, desde esta postura es frecuente que se considere que este conocimiento mantiene un carácter universalista como lo plantea Matthews (1994).

Ahora pensemos en la palabra humanizante, que etimológicamente en su estructura presenta los componentes léxicos -humanus (perteneciente a la tierra), -izare (convertir en), y -nte participio presente, que hace la acción. Raíces latinas que forman el significado: "hace la acción para dar características de lo humano". Humanizante, palabra directamente relacionada con humanizar y humanizada. Según Moliner (1967) humanizar es: "Hacer una cosa más humana, menos cruel, menos dura para los hombres”. El diccionario léxico (2019) considera 
que humanizar es: "Hacer que algo o alguien tenga un aspecto o naturaleza humana o muestre influencia de los seres humanos, o conferir carácter más humano (en el sentido moral), hacer algo más amable, justo o menos riguroso". Bajo esta perspectiva, en el marco de esta investigación, consideramos que las aproximaciones humanizantes sobre el conocimiento científico tienen que ver con:

El conocimiento científico es una construcción humana, que hace parte de la cultura, un saber que favorece algunas aproximaciones del mundo, elaborado en diversos lugares y épocas, que no es infalible, sino que presenta alcances y limitaciones. Un conocimiento parcial y dinámico en el que han sido partícipes elementos no racionales, como la creatividad, la intuición y la imaginación (Lederman, 2007). A su vez, en esta elaboración las relaciones sociales de los científicos, sus motivaciones y su contexto sociocultural, han jugado un papel importante. Es un conocimiento no jerárquico respecto a otros saberes que también intentan dar significado a la "realidad", el cual vale la pena ser enseñado respetando las diversas formas de ver el mundo.

¿Será posible que estudios de interpretación cultural de las ciencias, favorezcan concepciones y visiones humanizantes del conocimiento científico? En relación con este cuestionamiento, la investigación apuesta por abordar la postura de ciencia como sistema cultural, un planteamiento de Yehuda Elkana (1934-2012), que desde nuestra perspectiva podría aportar elementos destacables para favorecer concepciones humanizantes en el profesor.

Molina y Utges (2011) señalan que es clave avanzar en investigaciones que mejoren la comprensión cultural de las ciencias y llevar los resultados al proceso de formación. Si los esfuerzos por profundizar y humanizar las concepciones y visiones de los profesores de ciencias sobre el conocimiento científico tienen éxito, probablemente tales avances se verán reflejados en el desarrollo de su práctica de enseñanza, en el aprendizaje de sus estudiantes, y por ende, en una formación ciudadana de mayor pertinencia.

\section{Cambio didáctico en el profesorado de ciencias}

Las tendencias constructivistas sobre las que se fundamenta buena parte de la Didáctica de las Ciencias, en adelante DC, consideran que el aprendizaje de las ciencias representa cambios en las ideas, actitudes y prácticas previas y habituales de las personas (MOSQUERA; FURIÓ, 2008). De manera que desde las perspectivas constructivistas se considera que el aprendizaje conlleva a cambios conceptuales, actitudinales y procedimentales (GIL; MARTÍNEZ, 1987; GIL et al., 1991). El favorecimiento de estos cambios en los profesores de ciencias en relación con el conocimiento teórico y práctico construido, puede considerarse: un cambio didáctico (MOSQUERA; FURIO, 2008). 
Los profesores han ido aprendiendo de sus experiencias, inicialmente como estudiantes, y luego como maestros, pero poco se les ha formado científicamente para enseñar ciencias, aprendiendo en consecuencia a través de cómo les enseñaban sus profesores, de cómo enseñan sus compañeros principalmente aquellos que consideren relevantes, en definitiva, los profesores tratan de saber y saber hacer a partir de su socialización profesional (FURIÓ; CARNICER, 2002). Aún así, los profesores, a lo largo de sus experiencias, han construido creencias, saberes, actitudes y comportamientos, que, en conjunto, en la didáctica de las ciencias reciben nombres como epistemología personal docente, preconcepciones de sentido común sobre la enseñanza, teorías implícitas, pensamiento docente espontáneo, entre otros (FURIÓ, 1994).

El pensamiento docente espontáneo es para Tobin y Espinet (1989) aquello que los maestros ya saben sin siquiera saber que lo saben, es el pensamiento del sentido común de los profesores, un pensamiento que en repetidas ocasiones genera impedimentos para el desarrollo de una actividad docente innovadora y creativa. Gil (1991) señala que la influencia de esta formación es enorme ya que responde a experiencias reiteradas, sobre las que no se hace reflexión, aquellas que se toman como algo natural, algo obvio, convirtiéndose en obstáculos para la renovación de la enseñanza. Tobin y Espinet (1989); y Carretero y Limón (1997) indican que este tipo de pensamiento puede ser un obstáculo para el cambio didáctico, pero también es el punto de partida para su desarrollo.

Al reconocer que los profesores elaboran complejas maneras de pensar constituidas por sus experiencias, no necesariamente, por aquellas abordadas de manera consciente en su formación académica, sino que existen otras integradas de manera implícita, consideramos que es importante estudiar lo que piensa el profesorado de ciencias sobre la disciplina y todo lo que implique su práctica profesional, en particular, en los profesores que imparten en la formación de maestros, pues sus posturas reflexionadas o no, probablemente afloren en su práctica de aula, promoviendo entre las nuevas generaciones de profesores de ciencias la apropiación de diversas ideas sobre el conocimiento científico y su enseñanza.

Mosquera y Furió (2008) indican que en el profesorado de ciencias la epistemología personal docente integra una componente conceptual y otra actitudinal con respecto a las ciencias y a su enseñanza. Entre lo conceptual y lo actitudinal hay fuerte relación, pero al mismo tiempo profundas diferencias, pues al momento de diseñar estrategias de enseñanza una cosa es promover lo que sabe la persona y otra lo que cree e idea en relación con lo que sabe (MOSQUERA; FURIÓ, 2008).

La componente conceptual hace referencia a los saberes del profesor sobre la disciplina incluyendo su historia, su epistemología y sus condicionantes culturales, esto último corresponde, a las características sociales, políticas, económicas y académicas en las que están insertos los científicos, pero también, al reconocimiento del papel de la disciplina en el marco cultural específico. Igualmente, esta componente da cuenta de los saberes didácticos, y de los saberes del profesor sobre el currículo, la evaluación, las características de los 
estudiantes y su contexto, de modo que, concierne a los conocimientos elaborados en las actividades de investigación científica, así como en las de investigación científica escolar.

La componente actitudinal está asociada con las posturas personales y creencias del profesor sobre la disciplina, los valores o grados de aceptación o de rechazo sobre qué y cómo enseñar, sobre cómo aprender, y a las decisiones que conducen a la realización de prácticas concretas de enseñanza. Esta componente se fundamenta en aspectos personales que corresponden en buena medida a las vivencias de los profesores y sus formas individuales o grupales de ver el mundo, al reconocimiento de sí mismo, al reconocimiento de su labor, a sus intereses profesionales y a sus expectativas con respecto a la educación, y en particular, a la enseñanza y al aprendizaje de las ciencias.

Estudios en DC han concebido y contrastado dos factores claves para el cambio didáctico en el profesorado, uno de ellos son los cambios en la epistemología personal docente, el cual permite entender y construir estrategias que favorecen cambios conceptuales $\mathrm{y}$ actitudinales en los profesores; y el otro son los cambios en sus prácticas docentes, que permiten reflexionar en pautas curriculares para favorecer cambios procedimentales en el profesor (MOSQUERA; FURIÓ, 2008). Cabe señalar que estos cambios no son independientes, unos propician a los otros aunque no de manera definitiva ni lineal en todos los casos, ya que cada profesor y configuración educativa es única.

En el profesor de ciencias un cambio epistemológico orientado hacia concepciones menos rígidas y dogmáticas sobre la disciplina y su enseñanza, puede repercutir en que el profesor tenga perspectivas más abiertas y explore nuevas opciones didácticas; pero esto no garantiza que el cambio en las concepciones se manifieste en el aula como una conducta docente si no se transforman las actitudes, ni se dispone de saberes procedimentales apropiados para ponerlos en práctica con los estudiantes (FURIÓ; CARNICER, 2002; TOBIN, 1993).

El cambio didáctico es un proceso de transformación paulatino. Por tanto, la necesidad de mejorar la educación en ciencias no debe buscar soluciones simples que supongan una preparación compartimentada de actividades inconexas sobre conceptos a enseñar, y actitudes y prácticas sobre la enseñanza, pues con poco análisis y sin reflexión, se podría pensar que la formación del profesorado se subdivide en saberes académicos disciplinares, y de manera separada de conocimientos relativos sobre la enseñanza (FURIÓ, 1994). Los cambios conceptuales, actitudinales y procedimentales hacia la enseñanza son pertinentes con lo que ha de saber, saber hacer y hacer un profesor de ciencias, dichos cambios deben favorecerse simultáneamente como alternativa para hallar coherencia y articulación entre lo que piensa, predispone y hace el profesor (MOSQUERA; FURIÓ, 2008).

De no cambiar la epistemología docente en las fases iniciales de la formación, el cambio didáctico en el futuro será más complejo, ya que con la labor diaria se arraigan las prácticas profesionales. Delval (2002) afirma: “cambiar los profesores es algo 
extremadamente difícil. Por una parte, tienen sus hábitos de conducta y de enseñanza bien establecidos. Enseñan, sobre todo, como les enseñaron a ellos y, cuando se tiene una cierta práctica, resulta extremadamente difícil cambiar" (p. 79). En ausencia de alternativas claras, los profesores hacen uso de lo que adquirieron a través de sus vivencias, incluso aun cuando en la etapa de estudiantes rechazaban este tipo de prácticas docentes (FURIÓ et al., 1992). El carácter reiterado de la formación ambiental y su naturaleza del ejemplo vivo es mucho más eficaz que la explicación (FURIÓ; GIL, 1989). Mosquera y Furió (2008) señalan que la práctica profesional del profesor en ejercicio está impregnada por la formación ambiental fundamentada en la experiencia, por tanto, para considerar un modelo epistemológico personal docente que transforme la práctica es necesario conocer los conocimientos, las actitudes y las prácticas previas, para que a partir de estas y a través del aprendizaje permanente mediados por cambios, se promueva el desarrollo de nuevos conocimientos, actitudes y prácticas, que de la misma manera podrán ser susceptibles de nuevos cambios de acuerdo a las necesidades profesionales y sociales, así como a los desafíos del contexto.

Furió et al. (1992) consideran que el propósito del cambio didáctico no es la sustitución de la práctica pedagógica del profesor (por ineficiente que ésta sea), por otra con un enfoque más virtuoso, ya que si fuera así, esto otorgaría a la formación de maestros un carácter de común adoctrinamiento, y por el contrario de lo que se trata es cuestionar lo que se considera natural, haciendo ver que existen otras opciones, introduciendo posiciones críticas que den cuenta de la necesidad de un seguimiento de las innovaciones e investigaciones en didáctica de las ciencias.

Cada profesor puede reconocer los aspectos problemáticos de su práctica de enseñanza, analizar los efectos psicológicos personales frente a la situación y tomar conciencia de los riesgos y dificultades que lo llevan a realizar o no cambios (BELL; GILBERT, 1994). El cambio pocas veces implica el abandono completo de sus modelos didácticos por otros nuevos, más bien son adquisiciones parciales (GUNSTONE; NOTHFIELD, 1994; VALCÁRCEL; SÁNCHEZ, 2000). Los profesores no suelen realizar cambios radicales, sino que paulatinamente van incorporando a su práctica las ideas que les parecen asequibles, importantes y que al cabo de un tiempo consideran positivas (ARORA et al., 2000).

A continuación, se abordará el modelo de ciencia como sistema cultural, una postura con la que se busca favorecer cambios didácticos en el profesor universitario de física.

\section{Ciencia como sistema cultural}

\section{III.1 Noción de cultura en esta investigación}

Entre la multiplicidad de definiciones de cultura, se ha elegido la noción planteada por Geertz (1973, p. 5) quien señala: "el hombre es un animal suspendido en los entramados de significación que él mismo ha tejido". "Estos entramados son la cultura y que el análisis de 
ésta no es, en consecuencia, una ciencia experimental en búsqueda de una ley, sino una ciencia interpretativa en búsqueda de una significación" (GEERTZ, 1973, p. 5).

Esta postura antropológica simbólica deja de lado la trascendente hegemonía etnográfica, para dar prioridad a las interpretaciones plausibles del significado de las redes de la cultura, este planteamiento considera que los sujetos pueden interpretar la trama cultural de maneras diferentes, de acuerdo a su contexto y a sus condicionamientos sociales e individuales.

Geertz (1975, p. 8) afirma:

...si el sentido común es una interpretación de las inmediateces de la experiencia, un comentario hecho sobre los mitos, la pintura, la epistemología o cualquiera otra rama, entonces está históricamente construido, y sometidos a modelos de juicio históricamente definidos. Es así como el sentido común se puede cuestionar, discutir, afirmar, desarrollar, formalizar, contemplar, incluso enseñar, y él puede variar extremadamente de una persona a otra. Es pues, en sintesis, un sistema cultural...

La propuesta de Geertz sobre el sentido común motivó a Yehuda Elkana para considerar la ciencia como un sistema cultural.

\section{III.2 Interpretación cultural de la ciencia desde Yehuda Elkana}

Elkana (1981, p. 8) afirma:

Ya sea que queramos indicar por ciencia la suma total de las ideas sobre el mundo $o$, más estrechamente hablando como un conocimiento organizado, o también la ciencia como construcción histórica y que está sometida a estándares de juicio históricamente definidos, la ciencia puede ser cuestionada, discutida, afirmada, formalizada, enseñada, y sobre todo teniendo en cuenta que varía en forma extrema de una persona a otra; asimismo, en algunos puntos, puede variar de una disciplina a otra, y sin duda variar en forma extrema de una época a otra.

Posiblemente los defensores del cientificismo rechazarán la afirmación que la ciencia debe estar sujeta a estándares de juicio históricamente definidos, y aún más, cuando se señala que esta puede variar dramáticamente de una persona a otra (ELKANA, 1981). Los cientificistas consideran que el conocimiento es único e independiente del sujeto que lo estudie, en otras palabras, consideran que es externo al individuo.

Elkana (1981) es consciente que plantear la ciencia como un sistema cultural es controvertido, principalmente para la orientación cientificista del hemisferio occidental, ya que en general, la ciencia es la más importante dimensión de esta cultura, que se ha consolidado como la más racional. El autor para lidiar con aquella oposición propone que en 
un marco dado podría aplicarse el realismo, pero que el relativismo también es correcto, razón por la que no puede haber un marco global que sea externo a todos los demás marcos, que sea independiente de la cultura; el realismo y el relativismo simultaneo de la ciencia propuesto por el autor, se denomina pensamiento a dos niveles, que no es un enfoque donde todo vale.

El pensamiento a dos niveles tiene como fin evitar la polarización entre el enfoque realista y el relativista, en este pensamiento se puede y se debe ser realista con respecto al marco de conocimientos situado, pero al mismo tiempo se debe ser relativista en relación al marco cultural establecido, es un pensamiento que armoniza los dos niveles y quizá debería abordarse a la distancia de un tercer nivel, con el propósito de mantener una perspectiva equilibrada (ELKANA, 1981). Cuando en un determinado contexto cultural se promueven concepciones y visiones jerárquicas del conocimiento científico, difícilmente se da importancia a otras formas de pensamiento nacidas bajo contextos culturales diferentes, en la mayoría de casos sobrevalorando el propio pensamiento, y subvalorando el de otras culturas, más cuando se proclama la entera racionalidad y el desarrollo científico bajo fuentes de conocimiento como la experimentación, que poco dan la posibilidad para que otros aspectos no racionales sean reconocidos como parte de la construcción científica; una imagen del conocimiento que otorga pequeñas posibilidades al relativismo y que enuncia con orgullo su "realismo", que escasamente contempla que el "realismo" es relativo al contexto cultural. Con el propósito de afrontar epistemológicamente las dificultades presentes entre realismo y relativismo, Elkana (1981) señala:

1) La imposibilidad de ordenar objetivamente marcos de conocimiento, según su grado de racionalidad o de acercamiento a una verdad independiente de un contexto cultural.

2) La posibilidad, en un marco dado, de definir criterios de racionalidad y verdades relativas a este marco y ordenar el mundo en su interior según sus criterios.

El relativismo propuesto por Elkana, está asociado con el reconocimiento de las diferentes posturas, formas de vivir y de pensar en los diversos marcos culturales, sugiriendo situarlos para intentar comprender sus elaboraciones sobre la realidad, ya que los entramados de significación en los que se encuentra suspendida la humanidad, no son los mismos para todos, permitiendo construir diferentes interpretaciones del mundo, favoreciendo sobre éste la elaboración de diversos sentidos, que podrían promover creencias y orientar la toma de decisiones.

En los contextos culturales diferenciados no se comparten las mismas imágenes, fuentes y cuerpos de conocimiento, algo que posibilita la diversidad de significaciones sobre el mundo, posturas que en ocasiones presentan contraposición, generando tensiones que surgen porque en los marcos culturales frecuentemente se arraigan aproximaciones creadas, heredadas o apropiadas, posturas que si se afianzan de manera inamovible, calan en el sistema de creencias de las personas, reduciendo la posibilidad de situarse desde otra óptica cultural diferente, conllevando a cuestionar las posturas de otros desde las imágenes y fuentes de conocimiento de su propia cultura, una problemática que en muchos casos no permite 
trascender, denunciando carencia para lograr situarse aunque sea parcialmente en otro marco cultural. Si se logra ser consciente de esta dificultad, comprenderemos que las aproximaciones elaboradas sobre la "realidad" son relativas al marco cultural. Cabe destacar que en la propuesta de Elkana, hasta aquí es válido el relativismo.

Una vez situados en un contexto sociocultural específico, no se debería negar la "realidad", esta vale tanto al interior del mundo social, como para el mundo natural (ELKANA, 1981). Después de definidas las imágenes y las fuentes de conocimiento al interior del marco cultural, las elaboraciones sobre "la realidad" producto de esta configuración, poco otorgan espacio al relativismo, ya que estas construcciones dan cuenta al conjunto de elementos ya definidos para la elaboración del conocimiento al interior de ese marco. Realismo y relativismo, son una actitud intelectual y a su vez un comportamiento referencial, por tanto, la articulación entre estas se mantiene cuando las dos se sostienen simultáneamente (ELKANA, 1981).

La concepción cientificista sostiene que el conocimiento científico es transversal a cualquier contexto. En relación a este planteamiento Elkana (1981) señala que no existe una teoría de la cultura, porque si existiera posiblemente permitiría aplicar una plantilla a la multiplicidad de comportamientos humanos para realizarles análisis, de tal forma que el problema radicaría en hallar la plantilla que más se ajuste a todas las culturas, a todas las dimensiones culturales y para todos los tiempos, es decir, no puede existir ninguna teoría general de la cultura, lo que los filósofos de las ciencias denominan una teoría del conocimiento científico, dado que esto significaría que existe en algún lugar, un contexto global e independiente con respecto a todos los contextos con criterios que son eternamente verdaderos, razón por la que la ciencia vista como un sistema cultural no podría comprenderse bajo un contexto global, único, e independiente.

Las objeciones por parte de un colectivo que difiera de los planteamientos de Elkana podrían insistir, manifestando que esta postura aplicaría a la cultura en general o a la mayoría de sus dimensiones, dado que el arte es versátil, las ideologías se modifican, las religiones son múltiples, pero en relación a las ciencias habría una resistencia especial, con respecto a la cual Elkana (1981) denuncia la necesidad del desarrollo de la ciencia comparada.

La ciencia como sistema cultural fomenta respeto por la diversidad, al proponer el realismo y el relativismo, aspectos que permiten explicaciones alternativas sobre la realidad, teniendo en cuenta que esas maneras específicas de ver el mundo han sido creadas bajo condiciones particulares de un contexto cultural determinado.

La construcción científica comprende diversos factores, y no sólo aquellos que son promovidos por las aproximaciones habituales sobre el conocimiento científico tales como la razón y la experimentación. En contraste la ciencia como sistema cultural, reconoce de manera global otros elementos trascendentes para el trabajo científico, como el contexto, la 
diversidad en las maneras de pensar el mundo, de pensar las ciencias, acordes con las imágenes y fuentes de conocimiento propuestas en un lugar y época determinada.

\section{III.2.1 Imágenes y fuentes de conocimiento}

La cultura en la que se encuentran inmersos los individuos permite desarrollar posturas con relación al mundo que los rodea, y sobre el conocimiento que intenta dar significado a ese mundo. El conocimiento se desarrolla a través del diálogo crítico, entre las visiones totales del mundo que entran en competencia, con las de programas de investigación científica, algo que se puede distinguir a través de tres factores históricos analíticos, que sólo se pueden conocer si se detiene el tiempo y se fotografía la configuración sociocultural (ELKANA, 1981). Según Elkana (1981) dichos factores son:

a) El cuerpo de conocimiento: En cualquier época, lugar y cultura existe un estado de conocimiento con sus métodos, soluciones, problemas abiertos, redes teóricas, costumbres y formas de pensar que son compartidas y aceptadas por una parte de la comunidad científica, mientras que otras difieren de todos o algunos puntos acerca de sus visiones del mundo, de ellos mismos y de la sociedad. Entre las redes teóricas puede existir diálogo crítico, pero dependiendo del lugar, la cultura, el tiempo y la etapa de la ciencia posiblemente habrá programas de investigación dominantes. El diálogo crítico se desarrollará entre grupos con posturas diferentes, los temas de discusión girarán en torno a posiciones particulares sobre el conocimiento; no obstante, entre estos es probable que se generen acuerdos o divergencias, que no dependen necesariamente del cuerpo de conocimiento, sino que se encuentran influenciadas por las imágenes del conocimiento socialmente determinadas.

b) Las imágenes del conocimiento socialmente determinadas: Las creencias sobre los fines de las ciencias (comprensión, predicción...), sobre la naturaleza de la verdad (cierta, probable, alcanzable...), sobre las fuentes de conocimiento (por relevancia, por ratificación, por experimentos a través de los sentidos...), son parte de las imágenes de la ciencia, dependientes de la cultura, el lugar y el tiempo. La imagen de las ciencias es la que decide qué problemas elegir de la infinidad de problemas abiertos sugeridos para el cuerpo de conocimiento. Así es la determinación de la frontera de las ciencias. Las teorías, en su versión final, también se reducen a lo que por consenso social se decreta como una explicación aceptable. Las metodologías de igual manera son imágenes del conocimiento.

c) Ideologías, valores, normas y su relación con las imágenes del conocimiento: Los condicionamientos sociales, las políticas, las ideologías, las normas y los valores influyen en el apoyo brindado a las instituciones o a los programas de investigación científica. Las ideologías influyen en el surgimiento de las imágenes dominantes del conocimiento. Es solo a través de estas imágenes que tales consideraciones tienen un impacto en el cuerpo de conocimiento.

Las ideologías y los aspectos sociopolíticos en buena medida influyen en las posturas sobre el conocimiento, sobre sus fuentes, su legitimidad o aceptabilidad, en sí, sobre las 
imágenes de conocimiento que son criterios de selección para orientar el desarrollo investigativo del cuerpo de conocimiento (ELKANA, 1981). Los programas de investigación científica en competencia y sus concepciones del mundo, son consideradas metafísicas científicas enfrentadas, en las que las imágenes de conocimiento generan fuertes batallas ideológicas (ELKANA, 1981).

Elkana (1981) señala que las imágenes del conocimiento son puntos de vista sobre el conocimiento socialmente aceptado, siendo estas imágenes las que determinan para cada cultura los siguientes aspectos:

a) Las fuentes del conocimiento: Pueden ser el raciocinio, la experiencia, la revelación, la autoridad, la analogía, la tradición, la evidencia sensorial, la competencia, la originalidad, la novedad, la intuición, las ideas claras y distintas, la belleza, entre otras. Agregaríamos también la imaginación.

b) La legitimación del conocimiento: Según la cultura existe entre las diversas fuentes de conocimiento un orden jerárquico, y para ninguna dimensión cultural (religión, ciencias. política, entre otras) se toma en cuenta una única fuente del conocimiento, pero es a través de sus imágenes como se determina y legitima la fuente.

c) La audiencia o el público para el conocimiento: Algunas imágenes de conocimiento son multidisciplinarias y de amplia validez intelectual, mientras que otras son específicamente disciplinarias.

d) Ubicación en el secular sagrado: Existe una dependencia de la legitimidad del conocimiento en relación al marco teológico versus la estructura conceptual científica, tal dependencia obedece a las imágenes que se tengan del continuo sagrado-secular.

e) El continuo temporal: Hay imágenes de conocimiento que perduran durante siglos, algunas por décadas y algunas unos años solamente.

f) El grado de conciencia: Algunas imágenes de conocimiento son influyentes siempre y cuando se articulen completamente con otras. Cuando las imágenes tienen el papel de indicadores de calidad científica o de fundamento para la política científica, se debe reconocer entre indicadores implícitos y explícitos, así como entre indicadores inventados y descubiertos.

g) Relación con las normas, valores, ideologías imperantes: Los valores, las normas sociales de comportamiento, o ideologías pueden ser independientes de ciertas imágenes de conocimiento, mientras que otras posturas ideológicas posiblemente las determinan.

h) Traducibilidad de los enunciados acerca de la naturaleza: Algunas metafísicas se convierten con el tiempo en imágenes del conocimiento.

Con base a la organización anterior, emerge una estructura jerárquica de las imágenes del conocimiento, sobre las que Elkana (1981) señala: 
- Para cada dimensión cultural existen múltiples fuentes de conocimiento, y el ordenamiento de estas, es en sí una imagen de conocimiento interdependiente con el conocimiento que se considera de primera importancia.

- Las imágenes del conocimiento pueden modificarse en el transcurso del tiempo, lo cual implica que las jerarquías de las fuentes de conocimiento también se modifican de acuerdo a la coordenada temporal.

- La competencia se está convirtiendo en predominante jerárquica en las imágenes del conocimiento, que son determinantes para la elección de problemas en el cuerpo del conocimiento, son puentes buscados entre lo puramente social (valores, normas, ideologías) y los contenidos científicos.

Las imágenes del conocimiento determinan lo que se considerará importante, interesante, hermoso, que vale la pena, absurdo, armonioso, etc., de tal forma que los conceptos centrales de cualquier teoría del conocimiento y del cambio, son relativos a la cultura y al resultado del consenso social (ELKANA, 1981). En definitiva, las imágenes del conocimiento, que propone o asume cierta cultura, son determinantes para el presente y futuro de la actividad científica de esa comunidad.

Según Elkana (1981) las fuentes de legitimación del conocimiento dependen de las imágenes del conocimiento que varían en el espacio y el tiempo, de una cultura a otra; las fuentes se ordenan jerárquicamente teniendo en cuenta las que son generales y aceptadas en sociedades por amplios períodos, pero también aquellas que son de breve duración. Para el autor las fuentes del conocimiento, no necesariamente todas a la vez, son comunes para el desarrollo del cuerpo de conocimiento, sin embargo, la riqueza del contenido y la profundidad de la descripción, son sacrificados constantemente por estudiosos en pro de establecer relativa claridad en su intento de atribuir a cada dimensión cultural una fuente única de conocimiento. La construcción del cuerpo de conocimiento en cualquier dimensión de la cultura asocia diversas fuentes de legitimación, no obstante, la reconstrucción histórica en muchos casos presenta limitantes, al no asociar otras fuentes más que las convencionales, quedando ausentes algunas que podrían impulsar nuevas imágenes del conocimiento.

Elkana (1981) considera que el método científico es una simplificación excesiva, que si se acepta como fuente del conocimiento sería poco esclarecedora, pues promueve el error de expresar que las ciencias se fundan única y exclusivamente sobre los datos experimentales, sin considerar otras fuentes del conocimiento importantes en el campo científico como las ideas claras y distintas, las analogías, la novedad, la tradición, la estética, etc. Según el autor, los métodos son producto de las imágenes del conocimiento, sinónimos de la jerarquía de las fuentes aceptadas, tal es el caso de los métodos inductivos, deductivos, hipotético-deductivos, entre otros. En general, el reconocimiento de la propuesta de Elkana, podría favorecer condiciones para avanzar en concepciones y visiones humanizantes sobre el conocimiento científico. 


\section{III.2.2 Ciencia como sistema cultural y enseñanza de las ciencias}

Considerar la ciencia más objetiva e independiente de la normatividad social y de las imágenes de conocimiento trae consigo dificultades (ELKANA, 1981). Desde nuestro punto de vista, implicaría problemáticas asociadas con las concepciones y las visiones de la naturaleza científica, ya que se estaría promoviendo la ausencia del reconocimiento de las ciencias como construcción cultural con interdependencia social, aspectos que en ocasiones se refuerzan a través de la enseñanza. El físico austriaco Víctor Weisskopf, en contraste entre la enseñanza de un saber humanista y uno científico como la física manifiesta lo siguiente:

Comparé un curso de primer año en literatura. El maestro de literatura puede hablar directamente con el estudiante en términos de igualdad sobre las emociones $y$ pensamientos engendrados al leer una obra de arte en particular. El profesor de física no puede; él debe enseñar a corroer el lenguaje. En física, es un asunto unilateral: el profesor enseña, el estudiante aprende, mientras que, en la literatura, el estudiante y el profesor se encuentran en el mismo nivel de enfoque, si no de sofisticación (WEISSKOPF, 1976, p. 76).

Elkana (1981) señala que el problema radica en las imágenes anticuadas del conocimiento científico, específicamente las del positivismo que impactan la enseñanza de las ciencias, ya que según el autor esta postura no promueve una visión íntegra de esta elaboración, dedicándose principalmente a incentivar la técnica científica, a través de la unilateralidad en la que el maestro es el único dueño del conocimiento y el estudiante aprende lo que le ofrezca su profesor; por otro lado, Elkana también destaca que se han hecho esfuerzos por hacer más partícipes a los estudiantes, tal es el caso de la propuesta de aprender por descubrimiento, un planteamiento que intenta tomar al educando de la mano y en vez de dictarle la ley, pretende que él la descubra, una propuesta que presenta críticas pues no existe una única lógica precisamente configurada para que un sujeto realice un descubrimiento, además, en las aulas de clase no todos somos Newton.

Los enfoques tradicionales para la enseñanza de las ciencias poco contemplan nociones culturalistas de este saber, generando ausencia en la exploración de aspectos como el situar el conocimiento científico en el marco de la cultura, el reconocer la necesidad de su construcción en un contexto específico, el identificar la influencia sociocultural en la elaboración del cuerpo de conocimiento, así como reflexionar sobre sus alcances, sus limitaciones, su importancia e impacto en un determinado contexto, por tanto, si la enseñanza del conocimiento científico mantiene su enfoque tradicional, poco se abordarán aproximaciones humanizantes sobre las ciencias. El enfoque de enseñanza orientado por el positivismo promueve en los estudiantes imágenes de conocimiento limitadas, impulsando la noción de conocimiento científico alejado del contexto social, en ocasiones independiente de 
otros saberes, un conocimiento que promete la verdad acerca de cómo funciona el mundo, un tanto absolutista y con pretensiones jerárquicas con respecto a otras dimensiones culturales.

Elkana (1981) sugiere para la educación en ciencias que, en lugar de abordar los enfoques positivistas, se trabajen estudios de caso detallados, recreando la realidad de una situación histórica no solo sobre el cuerpo de conocimiento, sino que también sobre las imágenes del conocimiento. El autor considera que, en la enseñanza del conocimiento científico, la ciencia debe ser abordada como un sistema cultural, considerando que desde esa perspectiva se podrían construir a partir de las sugerencias del estudiantado, descripciones explicativas a problemas propuestos con el propósito de plantear una posible solución consensuada, buscando que los educandos participen activamente, aunque no con la misma sofisticación del profesor. Elkana no entra en detalles en relación a cómo debería ser explícitamente su propuesta para la educación en ciencias, no obstante, de su perspectiva se destaca la importancia que asigna a la continua participación del estudiantado en su proceso de formación de pensamiento científico, y el enfoque culturalista para enseñar este conocimiento.

El conocimiento científico escolar en su naturaleza posee multiplicidad de aspectos a tratar con los estudiantes, lamentablemente en muchas ocasiones las visiones cientificistas restringen el saber a unos cuantos aspectos, manifestando a los educandos implícita o explícitamente imágenes de conocimiento tan cerradas que para salir de estas se requiere de un gran esfuerzo. Siendo consecuentes con la postura de ciencia como sistema cultural, y con el propósito de abandonar los métodos tradicionales de enseñanza y aprendizaje de las ciencias, es necesario enseñar que el conocimiento es dinámico e incompleto, que es una aproximación del mundo, pero que además, en muchas ocasiones involucra creencias y vivencias en el marco de una cultura específica, aspectos que constituyen una imagen del conocimiento científico más reflexiva que podría facilitar procesos más conscientes en los educandos (ELKANA, 1983).

Si en los entornos escolares las ciencias se enseñan como un sistema cultural, quizá se estaría promoviendo en los estudiantes concepciones más íntegras sobre el conocimiento científico, posiblemente favoreciendo en ellos visiones más completas y diversas en cuanto a las maneras como se construye el conocimiento, identificando la importancia del contexto para el desarrollo de esta dimensión cultural, que presenta el mismo valor y reconocimiento que cualquier otra. La enseñanza de las ciencias puede promover la comprensión pública del conocimiento científico como parte de lo cultural y lo social, y responder con responsabilidad a los avances que generan la acelerada transformación en el mundo (ELKANA, 1983).

\section{Metodología}

Este trabajo es una investigación cualitativa donde se realizó Investigación Acción (IA), orientada por un estudio de caso de un profesor universitario que enseña en la formación inicial de maestros de física. En el marco de la IA, se llevó a cabo una fase inicial diagnóstica 
de la problemática, se realizó conceptualización de la información, se plantearon estrategias de acción con el propósito de favorecer cambios didácticos, se ejecutó una etapa de intervención con el profesor, se llevó a cabo un nuevo diagnóstico, indagando sobre los posibles cambios didácticos emergentes, y se analizaron los alcances obtenidos.

En seguida, se presenta un esquema que relaciona el tipo de investigación, con su correspondiente estrategia investigativa.

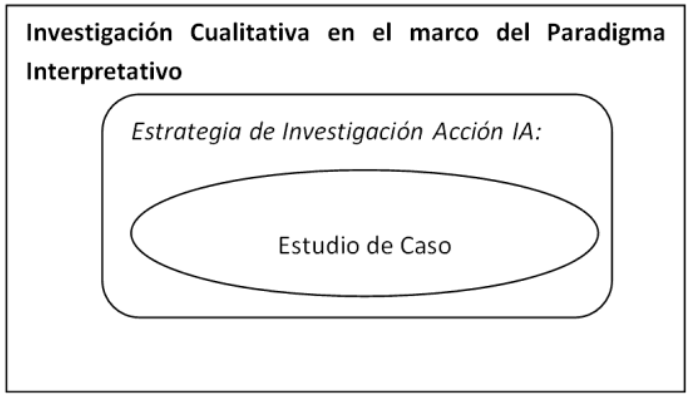

Fig. 1 -Esquema metodológico de esta investigación.

\section{IV.1 Diseño de la investigación}

A continuación, se presenta una tabla que sintetiza el diseño de investigación.

Tabla 1 - Protocolo metodológico.

\begin{tabular}{|c|c|c|c|c|}
\hline \multicolumn{2}{|c|}{ Fase de la investigación } & Actividad & Instrumento & Sujetos \\
\hline \multicolumn{2}{|c|}{ Fase previa } & $\begin{array}{l}\text { Búsqueda documental, revisión de } \\
\text { antecedentes, estudio de la literatura y } \\
\text { construcción del marco teórico y } \\
\text { metodológico de investigación. }\end{array}$ & $\begin{array}{l}\text { Libros y bases de datos: } \\
\text { Scopus, Doaj, ERIC, } \\
\text { Web of Science, Jstor, } \\
\text { ScienceDirect }\end{array}$ & Investigador \\
\hline \multirow{3}{*}{$\begin{array}{l}\text { IA. } \\
\text { (Inicio del } \\
\text { Estudio } \\
\text { de Caso) }\end{array}$} & \multirow{3}{*}{$\begin{array}{c}\text { Etapa } \\
\text { Diagnóstica }\end{array}$} & $\begin{array}{l}\text { Construcción de instrumentos } \\
\text { metodológicos para la obtención de } \\
\text { información y gestión para su } \\
\text { validación a través de expertos. }\end{array}$ & $\begin{array}{l}\text { Matrices de } \\
\text { observación, } \\
\text { y cuestionario }\end{array}$ & $\begin{array}{l}\text { Investigador } \\
\text { y Expertos }\end{array}$ \\
\hline & & $\begin{array}{l}\text { Observación de la práctica de aula del } \\
\text { profesor cuando enseña FC. Pilotaje } \\
\text { de las matrices de observación. }\end{array}$ & $\begin{array}{l}\text { Grabadora de audio, } \\
\text { matrices de observación }\end{array}$ & $\begin{array}{l}\text { Investigador, } \\
\text { profesor de } \\
\text { física } \\
\text { universitario. }\end{array}$ \\
\hline & & $\begin{array}{l}\text { Se implementan cuestionario y se } \\
\text { apoya la recolección de información } \\
\text { con la observación de clase. }\end{array}$ & $\begin{array}{l}\text { Grabadora de audio, } \\
\text { matrices de observación } \\
\text { y cuestionarios }\end{array}$ & $\begin{array}{l}\text { Investigador, } \\
\text { profesor de } \\
\text { física } \\
\text { universitario. }\end{array}$ \\
\hline
\end{tabular}




\begin{tabular}{|c|c|c|c|c|}
\hline $\begin{array}{c}\text { IA } \\
\text { (Estudio } \\
\text { de Caso) }\end{array}$ & $\begin{array}{l}\text { Etapa de } \\
\text { análisis de la } \\
\text { información } \\
\text { diagnóstica. }\end{array}$ & $\begin{array}{l}\text { Sistematización, indagación y análisis } \\
\text { de la información recolectada en la } \\
\text { etapa diagnóstica. Construcción del } \\
\text { diagnóstico sobre el profesor de física. }\end{array}$ & $\begin{array}{l}\text { Grabadora de audio, } \\
\text { matrices de observación }\end{array}$ & Investigador \\
\hline IA & $\begin{array}{c}\text { Etapa de } \\
\text { formulación } \\
\text { de estrategias } \\
\text { de acción } \\
\end{array}$ & $\begin{array}{l}\text { Formulación de estrategias de } \\
\text { intervención con enfoque en la ciencia } \\
\text { como un sistema cultural. }\end{array}$ & $\begin{array}{l}\text { Libros, artículos, } \\
\text { fuentes primarias }\end{array}$ & Investigador \\
\hline $\begin{array}{c}\text { IA } \\
\text { (Estudio } \\
\text { de Caso) }\end{array}$ & $\begin{array}{c}\text { Etapa de } \\
\text { intervención }\end{array}$ & $\begin{array}{l}\text { Se desarrollan sesiones de estudio con } \\
\text { el profesor en donde se abordan las } \\
\text { estrategias planificadas, y a su vez se } \\
\text { realiza seguimiento y adquisición de } \\
\text { información a lo largo del proceso de } \\
\text { intervención. }\end{array}$ & $\begin{array}{l}\text { Estrategias de } \\
\text { intervención, grabadora } \\
\text { de audio. }\end{array}$ & $\begin{array}{l}\text { Investigador } \\
\text { y profesor de } \\
\text { física } \\
\text { universitario. }\end{array}$ \\
\hline $\begin{array}{c}\text { IA } \\
\text { (Estudio } \\
\text { de Caso) }\end{array}$ & $\begin{array}{l}\text { Etapa de } \\
\text { Análisis de la } \\
\text { Información } \\
\text { sobre el } \\
\text { proceso de } \\
\text { Intervención }\end{array}$ & $\begin{array}{l}\text { Sistematización, indagación y análisis } \\
\text { de la información sobre el proceso de } \\
\text { intervención. }\end{array}$ & Grabadora de audio & dor \\
\hline $\begin{array}{c}\text { IA } \\
\text { (Estudio } \\
\text { de Caso) }\end{array}$ & $\begin{array}{l}\text { Etapa de } \\
\text { recolección } \\
\text { final de } \\
\text { información }\end{array}$ & $\begin{array}{l}\text { Se realiza de nuevo observación a la } \\
\text { práctica de enseñanza del maestro, se } \\
\text { implementa otro cuestionario } \\
\text { indagando sobre posibles cambios. }\end{array}$ & $\begin{array}{l}\text { Grabadora de audio, } \\
\text { matrices de } \\
\text { observación, } \\
\text { cuestionario }\end{array}$ & $\begin{array}{l}\text { Investigador } \\
\text { y profesor de } \\
\text { física } \\
\text { universitario. }\end{array}$ \\
\hline $\begin{array}{c}\text { IA } \\
\text { (Estudio } \\
\text { de Caso) }\end{array}$ & $\begin{array}{l}\text { Etapa de } \\
\text { triangulación y } \\
\text { análisis de la } \\
\text { información }\end{array}$ & $\begin{array}{l}\text { Se estudia la información obtenida } \\
\text { rastreando cambios en la } \\
\text { epistemología personal docente del } \\
\text { profesor, y cambios en las prácticas de } \\
\text { enseñanza de la FC. }\end{array}$ & $\begin{array}{l}\text { Grabadora de audio, } \\
\text { matrices de } \\
\text { observación, } \\
\text { cuestionarios, } \\
\text { estrategias de } \\
\text { intervención }\end{array}$ & Investigador \\
\hline $\begin{array}{c}\text { IA } \\
\text { (Estudio } \\
\text { de Caso) } \\
\end{array}$ & $\begin{array}{l}\text { Etapa de } \\
\text { reflexión sobre } \\
\text { los alcances de } \\
\text { la intervención } \\
\end{array}$ & $\begin{array}{l}\text { Se explora y reflexiona sobre los } \\
\text { alcances de la intervención. }\end{array}$ & $\begin{array}{l}\text { Grabadora de audio, } \\
\text { Matrices de } \\
\text { observación. }\end{array}$ & Investigador \\
\hline \multicolumn{2}{|c|}{$\begin{array}{l}\text { Fase Escritura de } \\
\text { Documento }\end{array}$} & Dar forma al documento final & Todos los anteriores & Investigador \\
\hline
\end{tabular}

\section{IV.1.1 Diseño de instrumentos para la recolección de información}

Un conjunto de indicadores de investigación estructuraron los instrumentos metodológicos con los que se buscó indagar en el profesor (matriz de observación, cuestionarios). La construcción de los indicadores fue fundamentada en los trabajos de (MOSQUERA; FURIÓ, 2008; FERNÁNDEZ et al., 2002; MOSQUERA, 2008; SUÁREZ, 2017; ZAPATA, 2017). 
La metodología de investigación es predominantemente cualitativa, sin embargo, sin perder su orientación, cuando fue necesario esta se enriqueció de múltiples elementos, razón por la que se integró cuestionarios tipo likert y el conteo de frecuencias para agrupar la información recolectada por las matrices de observación.

Para la etapa diagnóstica se diseñaron los siguientes instrumentos:

\section{Cuestionario 1}

Cuenta con 27 afirmaciones sobre visiones y concepciones de las ciencias y su enseñanza desde una perspectiva cultural, 22 de estas para puntuar, con una escala de 1 a 10 , donde 1 representa el menor y 10 el mayor grado de satisfacción. En el cuestionario también se presenta otro apartado con 5 afirmaciones, donde se solicita al profesor encerrarlas en una elipse si las consideraba correctas, pudiendo marcar más de una. Las afirmaciones encerradas recibieron un $5=$ Totalmente de acuerdo y las no encerradas un $1=$ Totalmente en desacuerdo.

\section{Matriz de observación de clase}

Para indagar sobre la integración de aspectos culturalistas en la práctica de enseñanza, se elaboró una matriz de observación. El instrumento presenta una versión diseñada para tomar información de una sola sesión de clase, y otra versión para agrupar la información de todas las sesiones observadas. Esta última hace uso de una escala que permite relacionar la frecuencia encontrada para cada criterio indagado. La escala respectiva es la siguiente: Nunca $=1$, Casi nunca $=2$, Frecuentemente $=3$, Casi siempre $=4$ y Siempre $=5$.

Para la etapa de recolección final de información, con base a los indicadores se abordaron los siguientes instrumentos:

\section{Cuestionario 2}

Para indagar de nuevo en las visiones y concepciones de las ciencias y su enseñanza desde una perspectiva cultural, se abordó un cuestionario similar al primero, pero las afirmaciones se plantearon en el marco de otro contexto, y en esta oportunidad, solo se cuestionó al profesor sobre los ítems que en el diagnóstico se situaron en las visiones y concepciones aculturalistas de las ciencias y su enseñanza.

\section{Matriz de observación de clase}

Se implementaron las matrices de observación para indagar sobre la posible integración de aspectos culturalistas en la práctica de enseñanza.

Los instrumentos metodológicos fueron validados por expertos y pares académicos, y en particular, con la matriz de observación se realizó una prueba piloto. Cabe señalar que la 
orientación metodológica para el análisis de los resultados de investigación, fue el análisis de contenido de Bardin (1996).

\section{Resultados y análisis de la etapa diagnóstica}

A continuación, se presentan algunos resultados obtenidos por cada instrumento metodológico, así como su respectiva triangulación para obtener un panorama más íntegro. Cabe destacar que las visiones y las concepciones de las ciencias y su enseñanza desde una perspectiva cultural, manifestadas en un entorno diferente al de la práctica de aula, se indagaron a través de un cuestionario buscando información sobre lo que piensa y lo que dice el profesor. En el caso de la indagación sobre la integración de aspectos culturalistas en la práctica de enseñanza, en donde se asocia lo procedimental, pero también lo conceptual y lo actitudinal, fue necesario examinarlo en el aula de clase in situ apoyado en la matriz de observación.

\section{V.1 Cuestionario 1. Visiones y concepciones de las ciencias y su enseñanza desde una perspectiva cultural}

En esta investigación se es consciente de las diferentes tendencias sobre las ciencias desde las perspectivas de diversidad cultural, Molina (2009) con el propósito de identificar algunas posturas señala:

1. En el multiculturalismo, se reconoce la importancia del conocimiento ecológico tradicional, y se cuestiona el universalismo del conocimiento científico, en esta propuesta se destacan los avances de Pomeroy (1992);

2. En el pluralismo epistemológico, se defiende que el conocimiento científico es una manera específica de conocimiento, sin embargo, se reconoce la existencia de otros tipos de conocimiento como el ancestral o tradicional que no deberían ser subvalorados, en este planteamiento se destaca el trabajo de los teóricos El-Hani y Bizzo (2002), y Cobern y Loving (2001). Así mismo, en su trabajo Adame y Mosquera (2016) comentan sobre las dos siguientes perspectivas culturales,

3. En la interculturalidad, se promueve el intercambio entre conocimientos de orígenes culturales diferentes, respetando la diversidad en las posturas que se plantean sobre los objetos de estudio, en el marco de este planteamiento sobresalen los desarrollos de Molina y Utges (2011);

4. En el contextualismo cultural, se plantea que el conocimiento científico debe entenderse en contextos culturales específicos, una apuesta que según Yuen (2010) favorece el proceso de enseñanza y aprendizaje, ya que desde esta postura se enfrentan específicas necesidades escolares situadas sobre la educación científica.

En el marco de esta investigación no se tiene como objetivo indagar de manera particular en alguna perspectiva de diversidad cultural, sino en general, la intención es 
explorar en el profesor, sus visiones y sus concepciones de las ciencias y su enseñanza desde una perspectiva cultural, especialmente en contraste con la visión universalista de las ciencias expuesta por Matthews (1994), postura que defiende que el conocimiento científico es transversal a cualquier contexto, argumentando que la realidad es la que tiene la última palabra al ser el juez de los enunciados propuestos, razón por la que desde esta perspectiva, se considera que las ciencias naturales presentan jerarquía epistémica con respecto a otros saberes, un planteamiento que se ha proliferado en las aulas bajo la noción de enseñanza habitual del conocimiento científico.

Luego de una sesión de clases, se solicitó al profesor diligenciar el cuestionario 1, posteriormente se contrastaron las afirmaciones con los indicadores, analizando las respuestas para detectar tendencias sobre las visiones y concepciones de las ciencias y su enseñanza desde una perspectiva cultural.

\section{Inferencias e interpretaciones}

El maestro considera que los conocimientos que fundamentan las ciencias poseen carácter universal. De manera que para el profesor las leyes y las teorías aplican para un sin número de contextos culturales, razón por la que los sujetos interesados en las ciencias deben compartir la misma unidad de pensamiento. Es decir, para el profesor las ciencias poseen un cuerpo único de conocimientos transversal a cualquier contexto, motivo por el cual difícilmente puede ser enseñada en perspectiva intercultural.

El profesor manifestó estar de acuerdo en que el contexto no influye en la actividad científica, parece que la interpretación que hace el maestro es que los problemas de las ciencias son particularmente de esa área de conocimiento, de modo que el contexto cultural, no los afecta, ni tiene implicaciones en la elaboración de sus posibles soluciones. Además, el profesor consideró que las ciencias no influyen en el contexto social, interpretándose en primera instancia escasa relación entre ciencias-tecnología-sociedad, considerando alejadas las ciencias de lo social, sin embargo, en el cuestionario más adelante se presenta otra afirmación que indica lo contrario, a lo que también el maestro señaló estar de acuerdo, planteando una contraposición entre las respuestas, quizá una interpretación distinta, o un cambio de posición. Por otro lado, el profesor considera que las ciencias son jerárquicas con respecto a saberes que plantean otras perspectivas de significación del mundo.

Las respuestas del profesor en la primera parte del cuestionario presentan afinidad con la perspectiva tradicional de las ciencias, donde el conocimiento científico se considera jerárquico y universal, en el que sus problemáticas son específicas de su área, y sus interacciones con el contexto social son escasas. Pero cuando en el cuestionario se presentó la afirmación las ciencias son parte de la cultura, la situación cambió, y el maestro tomó otra orientación, una más hacia lo cultural entrando en contradicción con algunas respuestas que 
ya había marcado, parece que la palabra cultura fue un detonante para tener otras apreciaciones sobre las ciencias. Después que en el cuestionario se relacionara de manera explícita las ciencias con la cultura, y se produjera un efecto detonante no planeado para un cambio de posición en el profesor, como si él hubiese caído en cuenta de algo, se mantuvo principalmente la orientación culturalista, aun cuando quedara en sus respuestas algunas contradicciones. En su nueva postura el profesor consideró que las ciencias son parte de la cultura, estando de acuerdo en que este desarrollo es una tentativa más entre otras que se han elaborado para dar significación del mundo, reconociendo que este saber es un proceso enmarcado en la construcción cultural, en el que para su elaboración ahora sí intervienen condiciones contextuales, así como aspectos específicos del sistema de creencias de los científicos, es decir, una orientación menos rígida, en la que se considera que se han desarrollado diversidad de conocimientos científicos, elaborados por sujetos de distintas épocas, construcciones bajo preceptos diferentes.

Es bastante particular el cambio de posición repentino del profesor sobre las visiones y concepciones culturalistas de las ciencias, la interpretación lleva a pensar que el maestro de alguna manera ha ido elaborando conocimientos al respecto, pero aún no se encuentran plenamente afianzados en su sistema de creencias, porque de ser así, desde la primer pregunta hubiese emergido una postura diferenciada de lo tradicional, algo que no se presentó, resultando finalmente el diligenciamiento del instrumento con algunas contradicciones.

Las visiones y concepciones culturalistas de la enseñanza de las ciencias del profesor, indagadas fuera del aula, manifestaron perspectivas sobre la integración de la orientación culturalista en la práctica de enseñanza. Al respecto se encontró que el profesor está de acuerdo en hacer explícito con los estudiantes que la actividad científica hace parte de la cultura. Además, que en la enseñanza de las ciencias en perspectiva cultural debe propiciarse el intercambio entre conocimientos de diversos orígenes culturales, reconociéndose la existencia de los saberes ancestrales y tradicionales provenientes de diferentes lugares. A su vez señaló estar de acuerdo en considerar el contexto educativo de los estudiantes para la enseñanza y el proceso de evaluación, específicamente teniendo en cuenta aspectos culturales de la población.

Algo que no fue concreto en las respuestas del maestro, fue si en la enseñanza de la física se debería exponer que las ciencias han sido influenciadas por el contexto de los científicos. Al parecer la relación entre la construcción del conocimiento científico y la influencia del contexto cultural donde estos se desarrollan, es ausente para el profesor.

Las respuestas del maestro no han facilitado la interpretación de este cuestionario dadas las contradicciones en algunos ítems. Lo que si queda claro es que el profesor necesita afianzar sus concepciones culturalistas de las ciencias y su enseñanza, después tomar posición sobre estas elaborando visiones al respecto, intentando establecer mayor claridad y una orientación definida sobre sus posturas. 


\section{V.2 Integración de aspectos culturalistas en la práctica de enseñanza del profesor, diagnóstico}

La observación se realizó en 40 sesiones de clase bajo la orientación del mismo profesor, 20 en el curso de Física Moderna y 20 en el curso de Mecánica Cuántica. Después de cada clase se diligenciaba la matriz de observación. La recolección de información fue apoyada en apuntes de clase en los que se registraba observaciones, y en grabaciones de audio que posteriormente se revisaron para extraer apartados relevantes para su análisis.

\section{Inferencias e interpretaciones}

La integración de aspectos culturalistas en la práctica de enseñanza de la Física Cuántica (FC) es mínima. Las pocas asociaciones que hace el profesor corresponden a las aplicaciones del conocimiento científico en la cotidianidad, pero él, no manifiesta relación explícita entre la FC y la cultura.

El profesor en su práctica manifiesta que el modelo de la física presenta limitantes, pues su construcción es reciente con respecto a la edad del universo y a la de la humanidad; señalando que este conocimiento no debe ser por sí mismo, sino que debería favorecer la vida del ser humano, procurando la explicación de fenómenos.

Entre los aspectos que relacionan de manera explícita la FC con la humanidad, el profesor acudió a las explicaciones que ha ofrecido este modelo como punto de partida para reflexionar sobre el problema energético, manifestando que se han propuesto posibles soluciones que se encuentran entre las aplicaciones de la FC, avances que intentan mejorar la calidad de vida de los seres humanos.

En la enseñanza el profesor manifiesta interacciones de la FC con otros saberes, mostrando que este conocimiento científico no es una isla, sino que se encuentra en continua relación con buen número de aspectos de la vida. En la práctica son destacables las reflexiones sobre cuestiones energéticas y la FC, relación que contextualiza el conocimiento y promueve en los estudiantes la toma de consciencia ambiental, algo importante para la formación de profesores de física. No obstante, esta dinámica de clase fue poco frecuente.

El profesor en sus explicaciones de manera implícita manifiesta que el conocimiento científico es un cuerpo de conocimiento jerárquico y trasversal a cualquier contexto, que no es necesario ubicarlo en un marco cultural específico. Es decir, para el profesor en la enseñanza, las ciencias fueron consideradas un conocimiento universalista, válido y enseñable de manera similar para cualquier contexto sociocultural.

\section{V.3 A modo de cierre de la etapa diagnóstica del profesor de física}

A manera de síntesis de la información encontrada, pero ahora realizando triangulación entre lo detectado con los instrumentos, se busca destacar lo siguiente: 


\section{V.3.1 Visiones y concepciones de las ciencias y su enseñanza desde una perspectiva cultural, diagnóstico}

Fuera de la práctica de enseñanza, el maestro se inclinó principalmente en el marco de las visiones y concepciones culturalistas de las ciencias, así como en las visiones y concepciones culturalistas de la enseñanza de las ciencias. Sin embargo, acorde a las acciones del profesor en la práctica de enseñanza se infiere que predominaron las visiones y concepciones aculturalistas de las ciencias, así como las visiones y concepciones aculturalistas de la enseñanza de las ciencias. Cabe señalar que en la enseñanza de la FC, no se hizo explícita la relación entre este saber y la cultura. Las relaciones cercanas que se establecieron, estuvieron asociadas a las aplicaciones de la FC en la cotidianidad de los seres humanos.

Tabla 2 - Visiones y concepciones de las ciencias y su enseñanza desde una perspectiva cultural. Diagnóstico.

\begin{tabular}{lll}
\hline Visiones y concepciones fuera de la práctica & Visiones y concepciones en práctica de enseñanza \\
\hline - & $\begin{array}{l}\text { Predominan visiones y concepciones } \\
\text { culturalistas de las ciencias. }\end{array}$ & Predomina visiones y concepciones \\
- $\begin{array}{l}\text { Predominan visiones y concepciones } \\
\text { culturalistas de la enseñanza de las ciencias. }\end{array}$ & aculturalistas de las ciencias. \\
& $\begin{array}{l}\text { Predominan visiones y concepciones } \\
\text { aculturalistas de la enseñanza de las ciencias. }\end{array}$ \\
\hline
\end{tabular}

\section{Proceso, resultados y análisis en la etapa de intervención}

\section{VI.1 Etapa de formulación de estrategias de acción}

En el marco de la IA, esta etapa fue diseñada a partir del diagnóstico. El propósito fue configurar estrategias de intervención que favorezcan cambios didácticos en el profesor, buscando enfrentar algunas dificultades detectadas en el estudio preliminar.

Con el objetivo de concertar cuáles dificultades abordar, fue necesario entablar diálogo con el profesor para mostrar los hallazgos detectados, luego procurar establecer acuerdos sobre lo que íbamos a enfrentar, decidiendo de manera mancomunada intentar potencializar la formación del profesor en una interpretación cultural de la ciencia. De acuerdo a este panorama se planearon y diseñaron un conjunto de actividades de intervención que se muestran a continuación:

Tabla 3 - Planificación de actividades para el proceso de intervención.

Objetivo: Favorecer cambios didácticos, en particular, concepciones humanizantes sobre el conocimiento científico en el profesor universitario de física, con el propósito de apoyar su formación continua, procurando la mejora en el desenvolvimiento de sus prácticas de enseñanza. 


\section{Material}

Descripción

Fecha

Documento (Diapositivas): Hallazgos encontrados en Socialización de los hallazgos de la la etapa diagnóstica. etapa diagnóstica. Diálogo y acuerdos sobre los aspectos a mejorar en la

Elaborado por: Cuesta, Y. enseñanza a través de la etapa de intervención.

\section{Sensibilización}

Documento (Diapositivas): Sobre el Diálogo. David Se realiza lectura y análisis del Bohm. Algunos Apartados. documento con el objetivo de favorecer

Basado en: Bohm, D. (2001). Sobre el diálogo. (D. condiciones adecuadas para el Sesión 2 González y F. Mora, Trad.). Barcelona, España: desarrollo del diálogo a lo largo del Editorial Kairós. proceso de intervención.

\section{Ciencia como sistema cultural}

\section{Videos:}

¿Qué es la Verdad?, Verdad y Contexto, Verdad y Lenguaje, Verdad, Sociedad y Cultura, Verdad y Lógica.

Referencias: Gershenson, C. (2019, febrero 14). ¿Qué es la verdad? [Archivo de video]. Recuperado de https://es.coursera.org/lecture/ciencia/que-es-la-verdadsp0VF

Gershenson, C. (2019, febrero 14). Verdad y Contexto [Archivo de video]. Recuperado de https://es.coursera.org/lecture/ciencia/verdad-y-contexto$\mathrm{UzETb}$

Gershenson, C. (2019, febrero 14). Verdad y Lenguaje [Archivo de video]. Recuperado de https://es.coursera.org/lecture/ciencia/verdad-y-lenguajeOchVX

Gershenson, C. (2019, febrero 14). Verdad, Sociedad y Cultura [Archivo de video]. Recuperado de https://es.coursera.org/lecture/ciencia/verdad-sociedady-cultura-QDxnx

Gershenson, C. (2019, febrero 14). Verdad y Lógica

[Archivo de video]. Recuperado de https://es.coursera.org/lecture/ciencia/verdad-y-logica-

UDx9N

\section{Preliminar:}

Se observan los videos y se dialoga sobre los mismos, intentando realizar un análisis mancomunado sobre estas temáticas propuestas en el curso virtual de Pensamiento Científico de la Sesión 3 Universidad Nacional Autónoma de México. Los videos se consideran oportunos pues en estos se resaltan posiciones culturales sobre el conocimiento científico (que sensibilizan y aportan para el trabajo a desarrollar en las siguientes sesiones).

Documento: Aproximación a la ciencia como sistema Se realiza lectura del documento y 
cultural. Parte 1

Basado en: Elkana, Y. (1981). A programmatic attempt at an anthropology of knowledge. En E. Mendelsohn y Y. Elkana. (Eds.), Sciences and Cultures. Anthropological and Historical Studies of the Sciences (pp. 1-76). Dordrecht, Holanda: Reidel Publishing Company.

Documento: Aproximación a la ciencia como sistema cultural. Parte 2

Basado en: Elkana, Y. (1981). A programmatic attempt at an anthropology of knowledge. En E. Mendelsohn y Y. Elkana. (Eds.), Sciences and Cultures. Anthropological and Historical Studies of the Sciences (pp. 1-76). Dordrecht, Holanda: Reidel Publishing Company.

Documento: Aproximación a la ciencia como sistema cultural. Parte 3

Basado en: Elkana, Y. (1981). A programmatic attempt at an anthropology of knowledge. En E. Mendelsohn y

Y. Elkana. (Eds.), Sciences and Cultures.

Anthropological and Historical Studies of the Sciences

(pp. 1-76). Dordrecht, Holanda: Reidel Publishing

Company.

En la planificación de actividades se integró un espacio de socialización diagnóstica y acuerdos, uno de sensibilización, y otro de interpretación de la ciencia como sistema cultural. Posturas que se trabajaron entre el investigador y el profesor sin condicionarlo para que las acogiera, o presionarlo para que las abordara en su aula de clases, la intención fue posibilitar el diálogo y la reflexión con el profesor a través de la negociación de significados.

\section{VI.1.1 Ciencia como sistema cultural, en la intervención}

Sesión 3. Sobre qué es la verdad: Con el propósito de favorecer el abordaje de la postura de ciencia como sistema cultural, se consideró pertinente, ver con el profesor los siguientes videos: 1. ¿Qué es la Verdad?, 2. Verdad y Contexto, 3. Verdad y Lenguaje, 4.Verdad, Sociedad y Cultura, y 5. Verdad y Lógica, herramientas audiovisuales expuestas por Gershenson (2019 a, b, c, d, e). Cabe destacar que la intención no fue estudiar las diferentes posturas sobre la noción de verdad, ni entrar en polémicas sobre el tema, sino abordar las explicaciones de Gershenson sobre la verdad ya que se consideraron destacables, porque desde nuestra perspectiva son afines con algunos planteamientos de Elkana.

En su material Gershenson (2019 a) expone que no hay definición de verdad que no sea debatible, señalando que a primera vista se podría decir que la verdad es lo opuesto a la mentira, sin embargo, reconoce que es difícil decidir que resulta mentira o no, indicando que 
sería más apropiado considerar la verdad como lo opuesto a la falsedad, resultando la verdad como algo que se ajusta con los hechos, es decir, con aquello que llamamos "realidad". El autor en su intención por definir aspectos sobre la verdad, manifiesta que los intentos por generar lenguajes que sean precisos sin dar lugar a ambigüedades, son planteamientos ideales, ya que no se puede alcanzar una precisión infinita, señalando que si quisiéramos ser completamente específicos sobre algo, nunca se terminaría el enunciado. Gershenson (2019 b) abordando el tema de las descripciones verdaderas, señala que estas no solo dependen de sí mismas, sino también del propósito para el que fueron diseñadas, agregando que no podemos manifestar nada sino es en el marco de un contexto, que el autor define como: "el conjunto de circunstancias y condiciones que rodean y determinan a una idea, teoría, proposición o concepto".

Dada la multiplicidad de contextos, coexisten diversas descripciones sobre los fenómenos en las que surgen distintas verdades que presentan una necesaria dependencia contextual. Al respecto Gershenson (2019 b) afirma:

\begin{abstract}
No podemos estudiar ningún fenómeno de forma puramente objetiva, ya que necesitamos una descripción, la cual depende de la perspectiva de un observador. Esto no quiere decir que el observador tenga una libertad absoluta para emitir distintas descripciones sino que hay una interdependencia entre el objeto u observado, entre el sujeto u observador y en la acción de observación o en la descripción, las cuales no podemos separar. Al tener distintas descripciones del mismo fenómeno, no podemos decir que una es verdadera y otra no, sino es dentro de un contexto, ya que tampoco podemos determinar la utilidad de distintos contextos de manera a priori, no podemos decir de manera absoluta que una descripción es mejor que otra.
\end{abstract}

Si retiramos una descripción de su marco contextual no necesariamente seguirá siendo válida, de manera que no se podría juzgar si algo es verdadero o no independientemente de un contexto, razón por la que si no somos afines con las ideas de otras personas, estas no se deberían juzgar desde nuestro propio contexto sino desde el suyo (GERSHENSON 2019 b). El autor agrega:

\footnotetext{
Podemos decir que la verdad tiene que estar de acuerdo con la realidad y que la realidad es independiente de un observador. Sin embargo, el significado y el conocimiento sí son dependientes de un observador. Ya que no podemos decir nada si no es con un lenguaje y desde el conocimiento, aunque en teoría digamos que la realidad es independiente del observador, no podemos decir nada sobre la realidad si no es como observadores (GERSHENSON 2019 b).
}

Según Gershenson (2019 c) el lenguaje se ha visto asociado con la comunicación, pero también, como una herramienta de conocimiento, no podemos decir nada si no es a partir 
de un lenguaje, sin éste, no podríamos razonar, ni pensar, de modo que para decidir si algo es verdadero o falso, se presenta dependencia con las reglas del lenguaje, aquel que es elaborado de manera sociocultural. Situando la "realidad" como independiente del sujeto y el conocimiento como una elaboración del observador sobre ésta, el lenguaje se convierte en el puente entre lo real y el conocimiento (GERSHENSON, 2019 c). De modo que, desde la perspectiva del autor las construcciones científicas, que por naturaleza están fundamentadas en el lenguaje, resultan ser aproximaciones sobre el mundo, más no explicaciones exactas.

La epistemología y la ontología permiten distinguir dos tipos de verdades, las nominales y las reales, al respecto Gershenson (2019 c) afirma:

\begin{abstract}
La palabra epistemología viene del griego epistémé, que quiere decir conocimiento o entendimiento y logos o estudio. La epistemología estudia directamente el conocimiento, cómo se adquiere, valida y qué límites tiene. La epistemología tiene una íntima relación con la filosofia de la ciencia, ya que aunque la ciencia trata de ser objetiva, la forma en la que adquirimos conocimiento depende de un lenguaje y también de la sociedad en la cual se adquiere este conocimiento. Podemos decir que dentro de la epistemología tratamos con verdades nominales, en otras palabras, con descripciones correctas de los fenómenos. La ontología estudia las cosas como son. La palabra viene del griego ontos que quiere decir ser y logos estudio. Podemos decir que la ontología trata de estudiar la realidad. ¿Qué es lo que existe? Podríamos decir que la ontología busca las verdades reales, pero cómo podemos describirlas si no es con un lenguaje y desde una perspectiva subjetiva.
\end{abstract}

Independientemente de lo que sea la "realidad", no podemos tener verdades nominales si no en el marco del contexto en el que se elaboró ese conocimiento, por otro lado, sobre las verdades reales no se puede decir nada si no es a través del lenguaje, es decir, existe una codependencia entre epistemología y ontología, entre verdades reales y nominales (GERSHENSON, 2019 c). De modo que el conocimiento sobre la "realidad" es limitado, pero, presenta importantes aproximaciones. Es así como en el marco de la física Gershenson (2019 c) para aclarar aspectos sobre los límites del conocimiento propone el siguiente ejemplo “...la ley de la gravitación universal es muy útil para calcular puentes, satélites, aviones. Sin embargo tiene sus límites, en otras palabras no es verdadera a escalas muy grandes o muy pequeñas".

Es importante encontrar en qué contexto son útiles las verdades, reconociendo que estas proposiciones presentan alcances y limitaciones. Según Gershenson (2019 d) las verdades dependen de los contextos como de los lenguajes, y tanto los contextos como los lenguajes son elaborados de manera histórica por las sociedades, de modo que no se puede alcanzar una verdad si no es en el marco de una cultura, que además, le otorgará sentido al conocimiento elaborado. Al respecto Gershenson (2019 d) señala:

Mis verdades no son sólo mías, son de mi sociedad y son de mi cultura. No son completamente objetivas ni completamente subjetivas. Dependen del contexto, 
dependen del lenguaje, dependen de la sociedad y también de la cultura en la que estemos. ¿Qué hacer si me enfrento a ideas o conocimientos que son distintos a los mios? Bueno, primero tenemos que ver si estamos usando el mismo lenguaje, quiere decir que tenemos el mismo significado, el mismo uso de las palabras. También tenemos que ver si estamos en el mismo contexto.

Según Gershenson (2019 e) cuando no compartimos el mismo contexto y el mismo lenguaje, es mejor reconocer las distintas posturas como perspectivas diferentes sobre el mismo fenómeno, sin entrar a considerar que la única verdad válida es la nuestra. Tal vez intentando complementar distintas verdades emergentes en diferentes contextos, podríamos realizar elaboraciones menos incompletas (GERSHENSON, 2019 e). Un proceso para el cual consideramos necesario que los actores en cuestión negocien sus significados.

El estudio y el diálogo sobre las posturas de Gershenson (2019 a,b,c,d,e), provocó en el profesor comentarios como el siguiente:

Profesor (P): Podríamos ponernos de acuerdo en que la verdad tiene que ver con el contexto, que la verdad del conocimiento depende del lenguaje, y que el conocimiento es una construcción colectiva, una construcción social.

Las reflexiones alcanzadas por el profesor y el investigador fueron destacables, ya que reconocieron la necesidad de ubicar los saberes de acuerdo al contexto, acordando que la verdad es relativa a ese marco, pero dependiente del lenguaje que presenta alcances y limitaciones. Vale la pena volver a enfatizar que estos acuerdos en el colectivo emergieron a causa del diálogo sobre las posturas de Gershenson (2019 a, b, c, d, e).

El acordar con el profesor que la verdad presenta dependencia con el contexto, se consideró un avance importante, porque permitió en la intervención mantener a las ciencias en el mismo nivel de importancia de otros saberes, es decir, se promovió que el conocimiento científico no es jerárquico, sino que presenta alcances y limitaciones como cualquier otra significación del mundo. Favoreciendo en el maestro la elaboración de concepciones más íntegras sobre las ciencias. Una atmósfera de estudio y de diálogo que se buscó mantener para enfrentar las visiones tradicionales sobre el conocimiento científico detectadas en el profesor en la etapa diagnóstica.

Investigador (I): Entonces podremos decir que la noción de verdad, así como la noción de conocimiento y su validez es dependiente del contexto.

P: ...ni la ciencia es totalmente objetiva. Yo no sé porque nos pusieron esa tarea a nosotros, no la vendieron así, y ese conocimiento tiene de todo. La ciencia es una construcción cultural que depende del lenguaje. 
Para la investigación es importante evidenciar que el profesor a través del proceso de intervención avanza en el reconocimiento de la ciencia como parte de la cultura, una perspectiva que destaca el valor de lo humano en el desarrollo del conocimiento científico. Más adelante, en el diálogo emergió:

P: (Sobre las ciencias). Por eso yo señalo, es una construcción colectiva, social y cultural, y eso tiene que ver con la mejora de la calidad de vida del ser humano.

De manera grupal con el profesor, nos pusimos de acuerdo en algunos de los que deberían ser los propósitos de las ciencias, integrando varios aspectos entre estos el progreso social y cultural. Avanzando en el diálogo, además se comentó:

I: ...y qué sucede con el conocimiento ancestral, el conocimiento del campesino, porque muchas veces al interior de la misma ciencia no se valora de la manera que corresponde.

P: Si, lo que no lo valora es la ciencia vista desde el punto de vista positivista. Porque hay mucho científico, que si valora este conocimiento acientífico.

I: O quizá científico pero bajo otro contexto.

P: Coloque la palabra que quiera, ciencia, conocimiento científico o simplemente conocimiento, como quiera, nos inventamos una frase que llamamos conocimiento científico, armando una cantidad de discursos alrededor de un nombre, lo cual hace mucha mella permeando el pensamiento...

En cuanto a las concepciones del profesor sobre las ciencias, se percibe distanciamiento de la postura positivista, comenzando a afianzar nociones culturalistas, reconociendo este saber como uno más que intenta explicar algunos aspectos del mundo. Un conocimiento como cualquier otro que se encuentra fundamentado en el lenguaje.

El profesor manifestó que para elaborar un conocimiento más consciente de lo qué son las ciencias, es necesario desarrollar procesos de reflexión profundos, que lo conlleven a reconocer que este conocimiento no es una verdad absoluta, sino que es una construcción en procura de posibles explicaciones sobre algunas cosas del mundo.

\section{Sesión 4, 5 y 6. Sobre la postura de Yehuda Elkana}

Con el objetivo de abordar la noción de ciencia como sistema cultural, de manera colectiva se estudiaron tres documentos: "Aproximación a la ciencia como sistema cultural". Parte 1, parte 2 y parte 3 . Luego de hacer lectura de los documentos y dialogar al respecto, se destacaron los siguientes comentarios:

P: Supongamos, cuando usted me dice que ve el semáforo gris, y yo lo veo verde. Siempre cuando las personas tienen un sistema de creencias rígido, dicen no, es que yo lo veo verde, yo nunca me pongo en la posición del otro... Entonces la idea sería tratar de situarme en el contexto del otro para ampliar esa noción de contexto, y ampliar esa noción de verdad... 
El trabajo previo de sensibilización a través de los videos expuestos por Gershenson (2019 a, b , c, d, e), permitió que el profesor rápidamente mostrara avances en la comprensión de las ideas propuestas por Elkana, nociones que a su vez el maestro pareció ir afianzando en sus sistema de creencias. El profesor en el diálogo hizo manifiesta la importancia de identificar el contexto desde el cual se plantean determinados conocimientos, ya que esto permitiría reconocer y ampliar la noción de verdad tenida en cuenta. Prosiguiendo con el diálogo se plantearon los siguientes comentarios:

P: (hablando sobre dogmas) Este problema del pensamiento científico no es propio de los científicos, es propio de la raza humana, de sus limitaciones, de las limitaciones del cerebro, porque el cerebro es muy fácil permearlo y dogmatizarlo.

I: Es la limitación de no comprender y no ponerse en la posición del otro, quien pertenece a un contexto cultural diferente, considerando que lo único que vale, es lo que uno piensa...

P: ...hinduistas, taoístas, musulmanes tienen sistemas de creencias rígidos, eso es común a la naturaleza humana, rigidizar el pensamiento, eso es terrible, porque las personas no elevan los niveles de consciencia para analizar lo que creen.

P: Hay gente que no cree en Dios, pero cree en otras cosas, gente que cree fervientemente en un modelo físico, en un modelo químico, al final todo lo común a eso, es que el afianzamiento de esas cosas en el sistema de creencias forma dogmas en la cabeza, y eso no es propio del pensamiento científico, es condición de la naturaleza humana.

En la intención de ponernos de acuerdo emergió la siguiente perspectiva: creer a ciegas en el conocimiento científico por el hecho de denominarse ciencia, es un dogma, que se va afianzando cuando se cree fervientemente en el modelo sin dar posibilidad a pensar sobre sus alcances y limitaciones. Pero la creencia a nivel dogmático no es una cuestión que se presente solamente en las ciencias, sino en otras dimensiones como la religión, la política, entre otras. Rigidizar el sistema de creencias es parte de la condición humana, de sus limitaciones, algo que nos ciega para situarnos desde la perspectiva de los otros, convenciéndonos que lo único evidente es lo que nosotros pensamos, alejándonos de la relación directa que existe entre contexto, conocimiento y verdad.

En parte de la comunidad científica es habitual que se crea que los modelos científicos son válidos para cualquier contexto sociocultural, considerando que estos son verdades absolutas y transversales sobre el mundo, posturas sobre el conocimiento científico que se afianzan y se rigidizan en el sistema de creencias de algunos sujetos, dificultando procesos de reflexión sobre la naturaleza de las ciencias. La creencia genera emoción y el ataque a la creencia genera resistencia, favoreciendo su defensa consciente o inconsciente de manera usual, sin reflexionar en el origen de la creencia, sin conocer críticamente con profundidad lo que se defiende y por qué se hace. Los sistemas de creencias rígidos van de la mano de los prejuicios, y estos conllevan a la antipatía y al rechazo anticipado de ideas distintas a las de las creencias. 
La elaboración del conocimiento en ciencias no escapa de las creencias fervientes de los científicos, bien sea sobre la dimensión religiosa, política y/o científica. Al respecto de esta última, cuando los modelos presentan aproximaciones destacables, algunos científicos tienden a creer en estos sin reconocer sus limitaciones, asumiendo su éxito parcial como verdad irrefutable, nociones que se van afianzando, favoreciendo la resistencia a los cambios de paradigma, como en el caso del surgimiento de la FC, donde un número importante de científicos se opusieron de manera rotunda a las nuevas ideas, por creer plenamente en el determinismo ofrecido por la física clásica.

Cuando las personas son capaces de observar desde otro ángulo su sistema de creencias rígido, pensando abiertamente en el porqué de su resistencia, cuestionándose los motivos por los qué está creyendo algo y no otra cosa, se favorece la elaboración de reflexiones, a través de las que se puede llegar a estados de consciencia que permiten abrir la posibilidad a pensar de manera diferente, favoreciendo la reevaluación y el abandono de algunas creencias, y a su vez posibilitando la elaboración de concepciones y visiones distintas, un proceso que puede ser complejo, y que podría estar interrelacionado con otras acciones del ser, tales como sus emociones y predisposiciones. Posteriormente el profesor agregó:

P: Si usted le pregunta a un físico por qué cuando una persona camina bambolea los brazos, quizá él le va a decir, porque se conserva momento angular, no, eso no es por eso, la vida es así. Por qué la tierra rota alrededor del sol, porque es así, así se dio, ahora que yo busque un modelo de explicación para construir máquinas, para poner satélites en órbita, eso es otro cuento, pero que esa sea la razón, no...

El profesor insistió en que el conocimiento científico no es la causa por la cual funciona el mundo, ni el cómo funciona, sino que corresponde a un conocimiento que propone una aproximación, un modelo que debería favorecer la calidad de vida de los seres humanos.

De manera colectiva se consideró que la postura positivista poco humaniza el conocimiento científico, ya que en este marco se enaltece para su elaboración la entera racionalidad, promoviéndose desde esa perspectiva un conocimiento obtenido por un método definido, que se ubica como un conocimiento jerárquico sobre otros saberes. En contraposición con esta perspectiva, el grupo de trabajo se situó en el marco de la ciencia como sistema cultural, una noción que entre sus múltiples características reconoce las diferentes fuentes de conocimiento para la elaboración de modelos explicativos acordes a contextos culturales específicos. Cabe señalar que en conjunto con el profesor se sugirió la necesidad de repensar la noción de ciencia habitual, con el objetivo de favorecer perspectivas holísticas sobre este conocimiento, lo que hizo que se otorgara mayor valor a la propuesta de Elkana, pues esta fue considerada una noción acorde con este propósito. 
A partir del trabajo colaborativo se ha logrado ampliar las nociones sobre el conocimiento científico en el marco de la cultura, señalando que esta elaboración no es jerárquica, sino que se encuentra al mismo nivel que otros saberes también importantes para el desenvolvimiento de una persona en la vida.

En conjunto se consideró necesario en la formación de profesores promover visiones más íntegras sobre el conocimiento científico, nociones que se distancien de la rigidez de las visiones tradicionales de las ciencias, no obstante, el equipo fue consciente de la complejidad de este trabajo, pues reconoció la dificultad para flexibilizar el sistema de creencias de las personas, más cuando estas ideas son frecuentemente reforzadas por influencias contextuales. De manera colectiva se atribuyó potencial al modelo de la ciencia como sistema cultural, para la formación de profesores de física, por considerar que este modelo favorece una noción más holística y humanizante del conocimiento científico.

\section{Resultados y análisis sobre la etapa de recolección final de información}

\section{VII.1 Cuestionario 2. Nuevo análisis, visiones y concepciones sobre las ciencias y su enseñanza desde una perspectiva cultural}

En este caso los indicadores indagados, en su gran mayoría fueron aquellos que en la etapa diagnóstica se situaron en las visiones y concepciones aculturalistas de las ciencias y su enseñanza, la intención fue reconocer si se presentaron cambios en las perspectivas del profesor luego de la intervención. Cabe destacar que el cuestionario se implementó aproximadamente un semestre después de este proceso.

\section{Inferencias e interpretaciones}

Luego de la intervención el profesor considera que el contexto cultural puede influenciar el proceso de elaboración científica. Pero además, es consciente que el conocimiento científico ha impactado de múltiples maneras algunos contextos culturales, no por eso, considera que este es superior, pues para el profesor, esta elaboración se encuentra al mismo nivel que otros saberes que intentan dar sentido al mundo.

El profesor señala que las ciencias no son un cuerpo universal de conocimiento válido para cualquier contexto cultural, razón por la que no se le puede tildar de transversal. Por otro lado, el profesor fue consciente que la idiosincrasia de los científicos ha jugado un papel importante en la construcción de este saber, aceptando que en las ciencias el raciocinio no es la única fuente de conocimiento.

El profesor manifiesta que el proceso de enseñanza de las ciencias debe adecuarse a las necesidades del contexto cultural de los estudiantes, algo que implica distanciarse de orientar las clases de ciencias, bajo los mismos contenidos y de la misma manera a cualquier 
grupo de educandos. En otras palabras, no sería lo mismo enseñar FC a futuros profesores de física que ha futuros ingenieros. Por otro lado, el profesor considera relevante que en la enseñanza de la FC, se manifieste que en la elaboración de ese conocimiento, la idiosincrasia de los científicos y otros elementos del contexto cultural fueron importantes, así como enseñar que no todo en el avance científico fue un proceso netamente racional.

El maestro señala que debido a que las ciencias no son un conocimiento universalmente válido para todos los contextos culturales, no aplica enseñarlo a todos de la misma manera, considerando que sería importante avanzar en el diálogo entre saberes de orígenes culturales diferentes, siendo consciente que en las diversas culturas se han construido múltiples propuestas que intentan darle sentido al mundo, desde diferentes puntos de vista.

Las respuestas del profesor, en comparación con las obtenidas en el cuestionario 1, cambiaron, distanciándose de manera más concreta de las visiones y concepciones aculturalistas de las ciencias y su enseñanza. En general, a través de este instrumento se evidenciaron cambios importantes en las visiones y concepciones del profesor, transformaciones con orientaciones próximas a perspectivas humanizantes del conocimiento científico.

\section{VII.2 Integración de aspectos culturalistas en la práctica de enseñanza del profesor, luego del proceso de intervención}

La observación se realizó en 25 sesiones de clase en el curso de Mecánica Cuántica bajo la orientación del profesor. Sesiones que se desarrollaron luego de la etapa de intervención. Las matrices se diligenciaron después de cada clase. La recolección de información fue apoyada en apuntes y en grabaciones de audio, que posteriormente se revisaron para extraer apartados que fueron analizados.

\section{Inferencias e interpretaciones}

Luego del proceso de intervención, el maestro por iniciativa propia integró aspectos culturalistas en la práctica de enseñanza de la $\mathrm{FC}$, en particular, se evidenció la postura de ciencia como sistema cultural planteada por Elkana.

El profesor manifestó a sus estudiantes que la verdad es relativa al contexto sociocultural, destacando que la física no es una verdad absoluta sobre el mundo, sino que es una de las posibles maneras de dar significación al mismo, señalando que es una aproximación con limitaciones, que surgen de las limitaciones propias del lenguaje, éste para él, es una elaboración colectiva a partir de la cual se construyen diferentes nociones. Bajo ese contexto todas las elaboraciones serían limitadas, restringidas por lo que puede ofrecer el lenguaje.

El profesor refiriéndose a la física en particular, señaló que sus modelos han sido de utilidad para intentar aproximarnos a algunos fenómenos, construcciones que han permitido 
resolver ciertas tareas, pero no por eso este saber es jerárquico frente a otras maneras de significación propuestas en otros contextos socioculturales.

El profesor señaló que en los diferentes contextos socioculturales, se han elaborado imágenes de conocimiento acordes a la construcción cultural, que orientan cuales deben ser las fuentes de conocimiento para elaborar nociones sobre el mundo, indicándole a sus estudiantes que los diversos saberes sobre la naturaleza elaborados por diferentes culturas, deben ser situados y validados bajo nociones particulares del contexto sociocultural específico.

El maestro en la enseñanza implícitamente consideró que en torno a la física se han elaborado imágenes y fuentes de conocimiento, que son reconocidas en ciertos contextos socioculturales, pero no por eso este saber debe ser jerárquico con respecto a otros, ni menos una verdad absoluta, ya que presenta limitaciones. El profesor señaló que es importante situar los saberes, pues estos son válidos bajo sus propios criterios. Es decir, para el profesor la física está hecha de modelos sobre el mundo, y este conocimiento solamente es "verdadero" bajo los criterios de esta disciplina.

El profesor manifestó que las matemáticas como lenguaje que se encuentra presente en la física, son importantes para ofrecer mayor precisión a este conocimiento, sin embargo, siendo consecuente con que el lenguaje presenta limitaciones, y las matemáticas son un lenguaje, entonces el maestro señaló que las matemáticas son limitadas para explicar el mundo, no por eso, dejó de destacar sus alcances en los modelos físicos.

En la práctica, el profesor hizo referencia a que el conocimiento en física ha sido elaborado a partir del lenguaje, que es una construcción colectiva, en la que se lleva a cabo negociaciones para lograr acuerdos, es decir, para el profesor en el proceso de construcción y de validación científica, es importante que la comunidad se ponga de acuerdo en el lenguaje, reconociendo que existen diferentes tipos de lógicas con las cuales se pueden enfrentar los problemas de la disciplina.

El profesor mostró a sus estudiantes que los modelos físicos de la FC presentan aproximaciones y restricciones. Según él, estos modelos bajo su contexto de verdad son válidos, y no porque se construyan otros más elaborados estos pasan a la categoría de falsos o de errores científicos, más bien son modelos elaborados bajo otras premisas, en el marco de otros contextos, presentando de igual manera alcances y limitaciones.

En la enseñanza el profesor manifestó que la verdad depende del contexto, razón por la cual no se debe asumir como absoluta o transversal, señalando que es un aspecto que se debe tener en cuenta para reconocer hasta donde una verdad tiene validez. Estas concepciones que el profesor expresó en clase, desde nuestra perspectiva, favorecieron nociones humanizantes del conocimiento científico en las futuras generaciones de profesores de física. 
El profesor comentó de manera crítica que algunas personas dedicadas a las ciencias naturales creen fervientemente en los modelos científicos, sin reconocer sus alcances y limitaciones, así como las necesidades por las que surgieron, considerando que el conocimiento científico es una verdad absoluta del mundo, válida para cualquier contexto sociocultural. Según él, cuando las ciencias desarrollan aproximaciones importantes, algunos sujetos que se desenvuelven en este campo, las asumen como verdades indiscutibles, rigidizando su sistema de creencias y dificultando el proceso de reflexión sobre la naturaleza de este conocimiento.

El profesor promovió en los estudiantes reflexiones para que sobre la física, no se afiancen creencias que nieguen la posibilidad de entender las ciencias como un emprendimiento humano con virtudes y limitaciones, un conocimiento que ha desarrollado aproximaciones destacables, pero que no por eso es jerárquico con respecto a otros.

El profesor señaló que en la educación, y en otros campos de conocimiento, buscamos hacer acuerdos en el lenguaje, para favorecer representaciones de ciertos aspectos de la humanidad y del mundo, a partir de las cuales se elaboran modelos que permiten desarrollar aproximaciones en diferentes ámbitos, no obstante, cuando los modelos se asumen como creencias sin reflexión, estas se convierten en prejuicios para comprender otras posturas, cayendo en la jerarquización del conocimiento, y en escasa posibilidad de lograr diálogo entre saberes.

En general, el maestro consideró que la noción de verdad es relativa al contexto, razón por la cual ha hecho referencia al marco de conocimiento situado, reconociendo que la física debe validarse en contextos socioculturales específicos, bajo el marco de sus imágenes y fuentes de conocimiento preestablecidas, pero que no debería compararse buscando algún tipo de jerarquía con respecto a otros saberes elaborados en contextos diferenciados, pues estos son producto de otras imágenes y fuentes de conocimiento. Por suponer una situación pensemos que tradicionalmente las fuentes de conocimiento de las ciencias son la racionalidad y la experiencia, pero en otro saber que también intenta dar significación al mundo las fuentes de conocimiento son la belleza y la intuición, entonces ¿cuál sería válido?, desde la perspectiva elaborada por el profesor los dos serían válidos, ya que esto depende del contexto sociocultural donde nos situemos, no obstante, cada una presenta maneras particulares de estructurarse y legitimar sus saberes.

En comparación con el diagnóstico, el profesor en la observación final, integró en sus clases de FC nociones de ciencia como sistema cultural, aspectos que consideramos favorecen en sus estudiantes la elaboración de reflexiones humanizantes sobre el conocimiento científico. 


\section{VII.3 A modo de cierre sobre la etapa de recolección final de información}

\section{VII.3.1 Visiones y concepciones de las ciencias y su enseñanza desde una perspectiva cultural, después de la intervención}

Tanto en su práctica de enseñanza como fuera de esta, el maestro se situó en el marco de las visiones y concepciones culturalistas de las ciencias, así como en las visiones y concepciones culturalistas de la enseñanza de las ciencias. Cabe destacar que el profesor en su discurso, frecuentemente consideró las ciencias como parte de la cultura, en particular, en el marco de la postura de ciencia como sistema cultural.

Tabla 4 - Visiones y concepciones de las ciencias y su enseñanza desde una perspectiva cultural, después de la intervención.

\begin{tabular}{ll}
\hline Visiones y concepciones fuera de la práctica & Visiones y concepciones en práctica de enseñanza \\
\hline - Predominan visiones y concepciones & - Predomina visiones y concepciones \\
culturalistas de las ciencias. & culturalistas de las ciencias. \\
- Predominan visiones y concepciones & Predominan visiones y concepciones \\
culturalistas de la enseñanza de las ciencias. & culturalistas de la enseñanza de las ciencias. \\
\hline
\end{tabular}

\section{Conclusiones}

\section{VIII.1 Cambios didácticos en el profesor de física, el papel de la ciencia como sistema cultural}

Para el estudio de la ciencia como sistema cultural en la formación permanente del profesor universitario de física, fue importante haber realizado sensibilización previa con base a lo expuesto por Gershenson (2019 a, b, c, d, e) sobre la verdad, verdad y contexto, verdad y lenguaje, verdad, sociedad y cultura, y verdad y lógica. Perspectivas que no son de estudio obligatorio antes de abordar la postura de Elkana, sin embargo, reflexionar en torno a estas favoreció la futura elaboración de concepciones sobre la ciencia como sistema cultural, permitiendo que el profesor reconociera que no existen verdades absolutas y transversales a cualquier contexto, sino que estas son relativas dependiendo el marco contextual y sociocultural, destacando que las verdades son construcciones en el lenguaje, y debido a que este presenta alcances y limitaciones, las verdades también las tienen.

El estudio de la ciencia como sistema cultural favoreció en el profesor concepciones y visiones humanizantes sobre las ciencias, considerando el conocimiento científico una construcción en el marco de la cultura, una elaboración en la que se proponen aproximaciones sobre el mundo a partir del planteamiento de modelos, sin embargo, no por eso las ciencias ofrecen verdades transversales sobre cómo funciona el mundo, ni tampoco estas son la causa 
por la cual este funciona. Además, el profesor demostró estar de acuerdo con el pensamiento a dos niveles en el que se puede ser realista con respecto al marco de conocimientos situado, pero en el que también se puede ser relativista en relación al marco sociocultural establecido, reconociendo que en los saberes elaborados en un contexto sociocultural específico, pueden considerarse ciertas verdades, pero válidas exclusivamente desde la perspectiva de un modelo particular.

El estudio del planteamiento de Elkana favoreció que el profesor considerara que en el marco de la cultura, se elaboran imágenes sobre el mundo circundante, y sobre el conocimiento que intenta dar significado a ese mundo, reconociendo que en los contextos socioculturales se construyen imágenes del conocimiento científico, que son elaboradas por la comunidad especializada y promovidas socialmente, imágenes que tienen que ver con las creencias sobre los fines de las ciencias, las perspectivas sobre la verdad, sus fuentes de conocimiento, sus metodologías y sus procesos de aceptación; pero además, se presentan ideologías, valores y normas que se relacionan con las imágenes del conocimiento, aspectos que repercuten en el apoyo brindado a las investigaciones, reconociendo que pueden forjarse ideologías que influyen en el desarrollo de imágenes dominantes del conocimiento.

El estudio de la ciencia como sistema cultural favoreció que el profesor considerara que las imágenes del conocimiento son puntos de vista socialmente aceptados, en los que para el proceso de elaboración de los saberes se destacan las fuentes de conocimiento, identificando que en las visiones habituales sobre las ciencias, se sobrevalora el papel de fuentes como el raciocinio y la experiencia, otorgando menos reconocimiento a otras como la intuición, la imaginación y la belleza.

La integración de aspectos sobre la ciencia como sistema cultural en la práctica de enseñanza, es uno de los aportes destacados luego del proceso de intervención. Se pudo evidenciar que por iniciativa propia del profesor, esta postura fue explícita desde la primera sesión de clases, asunto que se observó frecuentemente a lo largo del proceso de enseñanza, en particular, cuando se abordaron procesos de sensibilización sobre las concepciones del conocimiento científico. Un avance que creemos favorece visiones más sensatas sobre la disciplina en la formación inicial de profesores de física.

En general, el estudio de la ciencia como sistema cultural favoreció en el profesor de física perspectivas humanizantes del conocimiento científico, en las que se considera que este no es una verdad única, absoluta y transversal, válida para cualquier contexto sociocultural, sino que las ciencias resultan una tentativa interpretativa en búsqueda de significación del mundo, al igual que lo intentan hacer otros saberes como el mito, que en comparación con las ciencias posee otras imágenes y fuentes de conocimiento, no obstante, las interpretaciones que hacen cada uno de estos saberes son igualmente válidas, pero bajo específicos marcos situados. Teniendo en cuenta todo esto el profesor reconoció que las ciencias, en particular la física, es un conocimiento no jerárquico que se encuentra al mismo nivel de otros saberes que también intentan elaborar interpretaciones del mundo. 


\section{VIII.2 A Modo de cierre. Algunas recomendaciones para la formación del profesorado de física experto}

Se reconoce que cada investigación en educación es única, pero también se considera que éstas permiten pensar y repensar sus hallazgos en el marco de otros contextos, razón por la que nos aventuramos a recomendar en la formación del profesorado de física la incorporación de estudios sobre la ciencia como sistema cultural, apoyados en la noción de verdad expuesta por Gershenson (2019 a, b, c, d, e). Entre los posibles alcances destacamos los siguientes:

Tabla 5 - Posibles alcances del estudio de la ciencia como sistema cultural en la formación de profesores de física expertos.

- Favorece el cuestionamiento de la idea de verdad absoluta y transversal que en ocasiones proclaman las ciencias naturales.

- Favorece identificar que las verdades son relativas al contexto sociocultural.

- Favorece reconocer que las verdades son válidas en el marco de un contexto particular.

- Favorece identificar que las verdades son limitadas, como lo es el lenguaje con que estas son elaboradas y expresadas.

- Favorece el reconocimiento de la física como una elaboración en el marco de la cultura.

- Favorece nociones en las que el conocimiento científico se considera una elaboración humana que propone aproximaciones sobre el mundo, construcciones con alcances y limitaciones.

- Favorece reflexiones en las que se considera que las ciencias han sido desarrolladas con base a imágenes y fuentes de conocimiento predominantes en una época, sin desconocer que cuando los modelos no se ajustan, pueden elaborarse otras maneras de pensar, que podrían resultar en el surgimiento de un nuevo paradigma.

- Favorece comprensiones en las que se reconoce que el conocimiento científico puede variar de una época a otra, considerando que los modelos elaborados en este marco son aproximaciones del mundo, que podrían ser correctos bajo la estructura del propio modelo, no obstante, algunas de estas construcciones son más elaboradas que otras, y en ocasiones más trascendentes a nivel histórico, pero no por esto dejan de presentar limitaciones.

- Favorece la comprensión y el afianzamiento del pensamiento a dos niveles, en el que se puede ser realista con respecto al marco de conocimientos situado, pero en el que también se puede ser relativista en relación al marco sociocultural establecido.

- Favorece comprensiones en las que se sugiere que los saberes elaborados en un contexto sociocultural específico, pueden considerarse verdades en ese marco, sin embargo, estas son válidas exclusivamente bajo un modelo particular establecido, sin llegar a ser verdades absolutas y transversales del mundo.

- Favorece reconocer que los contextos socioculturales construyen imágenes del conocimiento científico, que son elaboradas por la comunidad especializada y promovidas socialmente, imágenes que están íntimamente relacionadas con las creencias sobre los fines de las ciencias, las perspectivas sobre la verdad, sus fuentes de conocimiento, sus metodologías y sus procesos de aceptación.

- Favorece identificar que las ideologías, valores y normas se encuentran relacionadas directamente con las imágenes del conocimiento científico. 
- Favorece que se considere que en las visiones habituales sobre las ciencias, se sobrevalora el papel de fuentes de conocimiento como el raciocinio y la experiencia, otorgando menos reconocimiento a otras como la intuición, la imaginación y la belleza, fuentes que también han sido determinantes para el desarrollo del conocimiento científico.

- Favorece nociones más holísticas del conocimiento.

- Favorece la no jerarquización del conocimiento científico con respecto a otros saberes que desde otras perspectivas también intentan dar significación al mundo.

La investigación permitió reconocer que el cambio didáctico no es repentino, sino que es producto de la reflexión permanente sobre el conocimiento que se imparte y sobre el proceso educativo. Ese cambio en toda su dimensión implica conocer de otras posturas, flexibilizar el sistema de creencias, para desrigidizar posiciones personales que se han reforzado con el tiempo, algo que si se logra, posibilita situarse en otras perspectivas diferentes a las habituales, sobre las que es necesario reflexionar, y si esto trasciende en el sujeto, es probable modificar sus actitudes, así como sus prácticas, una tarea realmente compleja.

Es importante comprender que los cambios en las concepciones, actitudes y prácticas podrían presentarse a corto plazo, quizá la rutinización del trabajo del profesor sobresalga volviendo a lo que habitualmente ha hecho. Por tanto, un asunto que puede explorarse en las investigaciones sobre el cambio didáctico es, ¿cómo favorecer que se mantengan los cambios en aquellos profesores, con los que se ha logrado avances destacables? Desde nuestra perspectiva investigativa, consideramos que posiblemente la integración de los maestros a equipos de trabajo donde se mantenga constante reflexión, favorece la consolidación de los cambios, y en general, el proceso de formación permanente del profesorado, de manera que lo habitual, sea la reflexión, quizá la innovación, pero no necesariamente lo tradicional. Sin embargo, estos son temas para futuras investigaciones.

\section{Referencias}

ADAME, J.; MOSQUERA, C. Concepciones de ciencia desde la perspectiva de la diversidad cultural: tendencias en profesores de ciencias naturales. Tecné Episteme y Didaxis: TED, Bogotá D.C., Número Extraordinario, p. 1718-1724, 2016.

ARORA, A.; KEAN, E.; ANTHONY, J. An interpretative study of a teacher's evolving practice of elementary school science. Journal of Science Teacher Education, London, v. 11, n. 1, p. 1-25, 2000.

BARDIN, L. EI análisis de contenido. Tradução: C. Suárez. Madrid: Ediciones Akal, 1996. $183 \mathrm{p}$. 
BELL, B.; GILBERT, J. Teacher development as professional, personal and social development. Teaching and Teacher Education, London, v. 10, n. 5, p. 483-497, 1994.

CARRETERO, M.; LIMÓN M. Problemas actuales del constructivismo. De la teoría a la práctica. En J. RODRIGO; J. ARNAY. (Org.). La construcción del conocimiento escolar (pp.). Barcelona: Paidos, 1997. p. 137-154.

CHALMERS, A. ¿Qué es esa cosa Ilamada ciencia? Madrid: Siglo XXI de España Editores S. A., 2000. 246 p.

COBERN, W.; LOVING, C. Defining "Science" in a Multicultural World: Implications for Science Education. Science Education, Nueva Jersey, v. 85, p. 50-67, 2001.

DELVAL, J. Entrevista a Juan Delval, realizada por P. Cañal. Investigación en la Escuela, Sevilla, v. 43, n. 1, p. 71-80, 2002.

DICCIONARIO LÉXICO. humanizar. Disponible en:

$<$ https://www.lexico.com/es/definicion/humanizar> Acceso en: 15 dic. 2019.

EL-HANI, C.; BIZZO, N. Formas de construtivismo: Mudança conceitual e construtivismo contextual. Ensaio Pesquisa em Educação em Ciências, Belo Horizonte, v. 4, p. 1-25, 2002.

ELKANA, Y. A programmatic attempt at an anthropology of knowledge. En E. MENDELSOHN y Y. ELKANA. (Org.). Sciences and Cultures. Anthropological and Historical Studies of the Sciences. Dordrecht: Reidel Publishing Company, 1981. p. 1-76.

ELKANA, Y. La ciencia como sistema cultural: una aproximación antropológica. (J. Granés, Trad). Boletín, Sociedad Colombiana de Epistemología, Bogotá, v. 3, n. 1, p. 65-80, 1983.

FERNÁNDEZ, I. et al. Visiones deformadas de la ciencia transmitidas por la enseñanza. Enseñanza de las Ciencias, Barcelona, v. 20, n. 3, p. 477-488, 2002.

FURIÓ, C.; GIL, D. La didáctica de las ciencias en la formación inicial del profesorado: una orientación y un programa teóricamente fundamentados. Enseñanza de las Ciencias, v. 7, n. 3, p. 257-265, 1989.

FURIÓ, C. Tendencias actuales en la formación del profesorado de ciencias. Enseñanza de las ciencias, Barcelona, v. 12, n. 2, p. 188-199, 1994. 
FURIÓ, C.; CARNICER, J. El desarrollo profesional del profesor de ciencias mediante tutorías de grupos cooperativos. Estudio de ocho casos. Enseñanza de las ciencias, Barcelona, v. 20, n. 1, p. 47-73, 2002.

FURIÓ, C. et al. La formación inicial del profesorado de educación secundaria: papel de las didácticas especiales. Investigación en la Escuela, v. 16, n.1, p. 7-21, 1992.

GEERTZ, C. Thick Description: Toward an Interpretive Theory of Culture. En: GEERTZ, C. (Ed.). The Interpretation of Cultures. New York: Basic Books, 1973. p. 3-32.

GEERTZ, C. Common Sense as a Cultural System. Antioch Review, Ohio, v. 33, n. 1, p. 526, 1975.

GERSHENSON, C. ¿Qué es la verdad? Disponible en:

$<$ https://es.coursera.org/lecture/ciencia/que-es-la-verdad-sp0VF>. Acceso en: 14 feb. 2019a.

GERSHENSON, C. Verdad y Contexto. Disponible en:

$<$ https://es.coursera.org/lecture/ciencia/que-es-la-verdad-sp0VF>. Acceso en: 14 feb. 2019 b.

GERSHENSON, C. Verdad y Lenguaje. Disponible en:

$<$ https://es.coursera.org/lecture/ciencia/que-es-la-verdad-sp0VF>. Acceso en: 14 feb. 2019c.

GERSHENSON, C. Verdad, Sociedad y Cultura. Disponible en:

$<$ https://es.coursera.org/lecture/ciencia/que-es-la-verdad-sp0VF>. Acceso en: 14 feb. 2019d.

GERSHENSON, C. Verdad y Lógica. Disponible en:

$<$ https://es.coursera.org/lecture/ciencia/que-es-la-verdad-sp0VF>. Acceso en: 14 feb. 2019e.

GIL, D.; MARTÍNEZ, J. Los programas guías de actividades: una concreción del modelo constructivista de aprendizaje de las ciencias. Investigación en la escuela, Sevilla, v. 3, n. 1, p. 3-12, 1987.

GIL, D. et al. La enseñanza de las ciencias en la educación secundaria. Barcelona: Horsori, 1991. 232 p.

GIL, D; MARTÍNEZ, J. Los programas guías de actividades: una concreción del modelo constructivista de aprendizaje de las ciencias. Investigación en la escuela, v. 3, n. 1, p. 3-12, 1987. 
GIL, D. ¿Qué hemos de saber y saber hacer los profesores de ciencias? (Intento de síntesis de las aportaciones de la investigación didáctica). Enseñanza de las ciencias, Barcelona, v. 9, n. 1, p. 69-77, 1991.

GUNSTONE, R.; NORTHFIELD, J. Metacognition and learning to teach. International Journal of Science Education, v. 16, n. 5, p. 523-537. 1994.

LEDERMAN, N. G. Nature of science: past, present, and future. In: S. Abell; N. LEDERMAN. (Org.). Handbook of research on science education. New Jersey: Lawrence Erlbaum Associates. 2007. p. 831-879.

MATTHEWS, M. Science teaching: The role of history and philosophy of science. Nueva York: Routledge, 1994. 277 p.

MOLINER, M. Diccionario de uso del español. Madrid: Gredos, 1967. v. 1.

MOLINA, A. et al. Diversidad cultural e implicaciones en la enseñanza de las ciencias: reflexiones y avances. Revista Colombiana de Educación, v. 56, p. 106-130. 2009.

MOLINA, A.; UTGES, G. Diversidad cultural, concepciones de los profesores y los ámbitos de sus prácticas. Dos estudios de caso. Revista de Enseñanza de la Física, Cordoba, v. 24, n. 2, p. 7-26, 2011.

MOSQUERA, C.; FURIÓ, C. El cambio didáctico en profesores universitarios de química a través de un programa de actividades basado en la enseñanza por investigación orientada. Didáctica de las ciencias experimentales y sociales, Valencia, v. 22, n. 1, p. 115-154, 2008.

MOSQUERA, C. El cambio en la epistemología y en la práctica docente de profesores universitarios de química. 2008. 610f. Tesis (Doctoral) - Universidad de Valencia, Valencia.

POMEROY, D. Science across cultures: Building bridges between traditional Western and Alaskan native cultures. En: S. HILLS (Org.). History and philosophy of science in science education, Ontario: Queen's University, 1992. v. 2. p. 257-268.

SUÁREZ, O. Recursos educativos abiertos como artefactos culturales: concepciones de los profesores de física que trabajan en la facultad de ingeniería. 2017. 371f. Tesis (Doctoral) - Universidad Distrital Francisco José de Caldas, Bogotá D.C. 
TOBIN, K.; ESPINET, M. Impediments to change: application of coaching in high school science teaching. Journal of Research in Science Teaching, Nueva Jersey, v. 26, n. 2, p. 105-120, 1989.

TOBIN, K. Referents for making sense of science teaching. International Journal of Science Education, United Kingdom, v. 15, n. 3, p. 241-254, 1993.

VALCÁRCEL, M.; SÁNCHEZ, G. La formación del profesorado en ejercicio. En: F. PERALES; P. CAÑAL. (Org.). Didáctica de las Ciencias Experimentales. Alcoy: Marfil, 2000. p. 557-581.

WEISSKOPF, V. Is physics human? Physics Education, New York, v. 11, n. 2, p. 75-79. 1976.

YUEN, C. Dimensions of diversity: Challenges to secondary school teachers with implications for intercultural teacher education. Teaching and Teacher Education, Amsterdam, v. 26, n. 3, p. 732-741, 2010.

ZAPATA, J. El contexto profesional en la enseñanza del electromagnetismo desde una perspectiva histórica en programas universitarios diferentes: implicaciones para el cambio didáctico. 2017. 294f. Tesis (Doctorado) - Universidad Distrital Francisco José de Caldas, Bogotá D.C. 